OPEN ACCESS

Edited by:

Steven E. Mock,

University of Waterloo, Canada

Reviewed by:

Alessandro Pepe,

University of Milano-Bicocca, Italy

Terrance Wade,

Brock University, Canada

${ }^{*}$ Correspondence:

Mashhood A. Sheikh

mashhood.a.sheikh@uit.no

Specialty section: This article was submitted to

Developmental Psychology, a section of the journal

Frontiers in Psychology

Received: 03 February 2016 Accepted: 29 April 2016 Published: 25 May 2016

Citation:

Sheikh MA, Abelsen B and Olsen JA (2016) Clarifying Associations between Childhood Adversity, Social Support, Behavioral Factors, and Mental Health, Health, and Well-Being

in Adulthood: A Population-Based Study. Front. Psychol. 7:727. doi: 10.3389/fpsyg.2016.00727

\section{Clarifying Associations between Childhood Adversity, Social Support, Behavioral Factors, and Mental Health, Health, and Well-Being in Adulthood: A Population-Based Study}

\author{
Mashhood A. Sheikh *, Birgit Abelsen and Jan A. Olsen \\ Department of Community Medicine, University of Tromsø, Tromsø, Norway
}

Previous studies have shown that socio-demographic factors, childhood socioeconomic status (CSES), childhood traumatic experiences (CTES), social support and behavioral factors are associated with health and well-being in adulthood. However, the relative importance of these factors for mental health, health, and well-being has not been studied. Moreover, the mechanisms by which CTEs affect mental health, health, and well-being in adulthood are not clear. Using data from a representative sample ( $n=12,981$ ) of the adult population in Tromsø, Norway, this study examines (i) the relative contribution of structural conditions (gender, age, CSES, psychological abuse, physical abuse, and substance abuse distress) to social support and behavioral factors in adulthood; (ii) the relative contribution of socio-demographic factors, CSES, CTEs, social support, and behavioral factors to three multi-item instruments of mental health (SCL-10), health (EQ-5D), and subjective well-being (SWLS) in adulthood; (iii) the impact of CTEs on mental health, health, and well-being in adulthood, and; (iv) the mediating role of adult social support and behavioral factors in these associations. Instrumental support $(24.16 \%, p<0.001)$ explained most of the variation in mental health, while gender $(21.32 \%, p<0.001)$ explained most of the variation in health, and emotional support $(23.34 \%, p<0.001)$ explained most of the variation in wellbeing. Psychological abuse was relatively more important for mental health (12.13\%), health (7.01\%), and well-being (9.09\%), as compared to physical abuse, and substance abuse distress. The subjective assessment of childhood financial conditions was relatively more important for mental health (6.02\%), health (10.60\%), and well-being (20.60\%), as compared to mother's and father's education. CTEs were relatively more important for mental health, while, CSES was relatively more important for health and wellbeing. Respondents exposed to all three types of CTEs had a more than two-fold increased risk of being mentally unhealthy $\left(R_{\text {Total Effect }}=2.75,95 \% \mathrm{Cl}: 2.19-3.10\right)$, an $89 \%$ increased risk of being unhealthy $\left(R_{R_{\text {Total Effect }}}=1.89,95 \% \mathrm{Cl}: 1.47-\right.$ 1.99), and a $42 \%$ increased risk of having a low level of well-being in adulthood 


\begin{abstract}
$\left(R_{\text {Total Effect }}=1.42,95 \% \mathrm{Cl}: 1.29-1.52\right)$. Social support and behavioral factors mediate $11-18 \%(p<0.01)$ of these effects. The study advances the theoretical understanding of how CTEs influence adult mental health, health, and well-being.
\end{abstract}

Keywords: psychological violence, emotional abuse, mental abuse, verbal aggression, verbal abuse, stress, early life stress, child maltreatment

\section{INTRODUCTION}

A significant amount of research on health and well-being has focused on assessing the influence of social support factors and behavioral factors (Armstrong, 2009). The theoretical debate in social sciences centers on the relative importance of structure and agency in determining these social support and behavioral factors. For instance, whether people's decisions about smoking, alcohol use, and making friends are shaped by structural conditions like gender, childhood socioeconomic status (CSES), childhood traumatic experiences (CTEs) etc., or if such decisions are largely a matter of agency-driven individual choices. The empirical evidence lags behind the theoretical development, and empirical evidence linking structural conditions with agency is scarce. Previous studies have shown that CSES, psychological abuse (also referred to as psychological violence, emotional abuse, mental abuse, verbal abuse, or exposure to verbal aggression) and physical abuse in childhood (also referred to as physical violence), and social support and behavioral factors in adulthood are associated with mental health, health, and well-being in adulthood. However, the relative contribution of these structural conditions to social support and behavioral factors, and mental health, health, and well-being has not been studied previously. We address this question by using the Shapley (Shapley, 1953) decomposition of the dissimilarity index (Hoyos and Narayan, 2011) and $R^{2}$ (Huettner and Sunder, 2012) proposed by Shorrocks (1982, 2012) (see also Barros et al., 2009, 2010).

Furthermore, the mechanisms by which CTEs affect mental health, health, and well-being in adulthood are not clear. The "life course" epidemiology theory proposes the "chains of risk" model (Ben-Shlomo and Kuh, 2002), which is relevant to understanding the effect of CTEs on adult mental health, health, and well-being. Risk factors for poor health and well-being in adulthood, such as CTEs, having no social support in adulthood, smoking, and alcohol abuse, may accumulate over time as chains of risk. Each adverse experience (or exposure) tends to lead to another, and so on. In this way, different exposures or adverse experiences in life accumulate over time in an additive manner. Victims of CTEs may be more likely to encounter subsequent stressors in adulthood.

CTEs are associated with social support and behavioral factors in adulthood, including difficulties in adult interpersonal relationships and poor social conformity (Robins, 1978; Cole and Putnam, 1992; Luntz and Widom, 1994; Silverman et al., 1996; Davis et al., 2001; Horwitz et al., 2001; Schilling et al., 2007; Daruy-Filho et al., 2011; Huh et al., 2014; Krastins et al., 2014; Gayer-Anderson et al., 2015), increased risk of higher alcohol use (Miller et al., 1993; Widom et al., 1995; Fergusson and Lynskey, 1997; McCauley et al., 1997; Widom and White, 1997; Felitti
Md et al., 1998; Hussey et al., 2006; Shin et al., 2015), smoking (Felitti Md et al., 1998; Hussey et al., 2006), and a wide range of mental health problems (Heim and Binder, 2012; Norman et al., 2012; Gilman et al., 2015), which may also affect health negatively (McLaughlin et al., 2010; Shonkoff and Garner, 2011). Thus, social support and behavioral factors in adulthood shape later health and well-being, but they are also influenced by antecedent conditions (Schilling and Christian, 2014). This implies that disadvantages in health that are associated with social support and behavioral factors in adulthood may be contingent upon the structural situations that provoked and shaped these factors in the first place.

When the results of previous studies on the role of social support factors in adulthood as mediators in the CTEs-health association are considered, the dominant conclusion is that victims of CTEs may display antisocial behavior (or may have developed an antisocial personality disorder) as a consequence of CTEs. The Diagnostic and Statistical Manual of Mental Disorders (5th edn; DSM-5) describes abuse during childhood as one of the predisposing factors for antisocial personality disorder (American Psychiatric Association, 2013). Thus, it may not be the lack of social support network that mediates the CTEs health/well-being association; rather, it may be the incapacity to maintain a social support network, which in turn affects health and well-being negatively. In this way, social support factors in adulthood may serve as a crude proxy for antisocial behaviors or disorders. This raises an important, yet rarely addressed question: is the influence of CTEs on adult health and wellbeing independent of social support and behavioral risk factors in adulthood? These associations are probabilistic rather than deterministic and the chain of risk may be broken by intervening on the mediators, but a residual damage may remain in the form of direct effects. Only a few studies (Shaw and Krause, 2002; Dong et al., 2003; Springer, 2009; Morton et al., 2014; Salinas-Miranda et al., 2015) have assessed the mediating role of social support factors and behavioral factors in the CTEshealth association, and the results were not consistent. Behavioral factors, such as smoking and a higher alcohol use, may serve as coping mechanisms or as self-medication for victims of CTEs, leading to increased health risks in adulthood (Briere, 2002; Morton et al., 2014).

Several studies (Felitti Md et al., 1998; Dube et al., 2001; Edwards et al., 2003; Schilling et al., 2007; Hovens et al., 2010; Raposo et al., 2014) have assessed the effect of childhood adversity on adult outcomes by assigning a score constructed by counting the stressors that occurred. However, this approach assumes that each type of CTE has an equivalent weight, and that there is an additive effect, when in fact some CTEs may have a stronger effect than others, and there may not be any additive effect 
(Cohen et al., 1997; Martin et al., 2006; Schilling et al., 2008). For instance, previous studies have shown that psychological abuse has a greater negative effect on mental health and health in adulthood, as compared to physical abuse in childhood (Ney, 1987; Martin et al., 2006; Norman et al., 2012; Dias et al., 2014; Spinazzola et al., 2014; Auslander et al., 2015; Friborg et al., 2015).

Furthermore, are the effects of different adversities in childhood distinct from one another? Since different adversities may be correlated, interact, and co-occur in the same individuals, is there an independent and unique effect of each indicator of CTEs on adult mental health, health, and well-being? Only a few studies (Mullen et al., 1996; Greenfield and Marks, 2009, 2010; Slopen et al., 2010; Dias et al., 2014; Thoresen et al., 2015) have considered (though it was not explicitly stated in most of them) the inter-dependence (multiplicative interaction) between different types of CTEs, and the results were not consistent. This may be because the low prevalence of CTEs make interactions difficult to detect in small samples.

Many studies have relied on high-risk samples, treatmentseeking samples, diagnosed patient samples, and reported cases (Alloy et al., 2006; Gaudiano and Zimmerman, 2010; Saunders and Adams, 2014; Cancel et al., 2015; van Dam et al., 2015). These samples are more prone to selection bias, and are not helpful in making population estimates (Chartier et al., 2010; Saunders and Adams, 2014). It is difficult to establish whether social support and behavioral factors in adulthood in general are involved in the etiology of health outcomes from these samples.

The influence of CTEs extends to single-item self-rated health (Felitti Md et al., 1998; Hussey et al., 2006; Fagundes and Way, 2014; Salinas-Miranda et al., 2015) and psychological well-being (Greenfield and Marks, 2010; Nurius et al., 2015) in adulthood. Previous studies have shown that the single-item, self-rated health questions are an unreliable measure of health (Crossley and Kennedy, 2002; Zajacova and Dowd, 2011), in contrast to disease-specific or symptom-specific measures of health (Sheikh et al., 2016). Similarly, over $70 \%$ of the variation in the single-item global life satisfaction question is driven by the mood we are in at the very moment we are asked the question (Seligman, 2012).

Few previous studies (Felitti Md et al., 1998; Walker et al., 1999; Edwards et al., 2003; Agorastos et al., 2014) have assessed the association between CTEs and quality of life in adulthood. However, no previous study was found that assessed the influence of CTEs on a validated generic descriptive system for healthrelated quality of life (HRQoL) such as the Euroqol 5 dimension scale (EQ-5D), or subjective well-being (SWLS) in adulthood.

\section{AIMS OF THE STUDY}

In this study, we assessed (i) The relative contribution of structural conditions (gender, age, CSES, psychological abuse, physical abuse, and substance abuse distress) to social support and behavioral factors in adulthood; (ii) the relative contribution of socio-demographic factors, CSES, CTEs, social support, and behavioral factors to three multi-item instruments of mental health (SCL-10), health (EQ-5D), and subjective well-being (SWLS) in adulthood; (iii) the impact of CTEs on mental health, health, and well-being in adulthood, and; (iv) the mediating role of adult social support and behavioral factors in these associations.

\section{DATA AND METHODS}

\section{Study Population}

Tromsø is the largest city in Northern Norway, with more than 70,000 inhabitants. The Tromsø Study is a prospective cohort study of the population residing in the municipality of Tromsø that is considered representative of the adult population there (Jacobsen et al., 2012). Between 1974 and 2007/2008, six waves of the Tromsø Study were conducted (referred to as Tromsø IVI). The current paper is based on data from the sixth wave, conducted in $2007 / 2008$. For this wave 19,762 subjects were invited; 12,984 (65.7\%) returned the questionnaire (6054 men and 6930 women, born between 1920 and 1977). The study design has been described previously in detail (Jacobsen et al., 2012).

\section{Measures of Mental Health, Health, and Well-Being}

Mental health status was measured by the Hopkins Symptoms Check List-10 (SCL-10), which is widely used in epidemiological studies. Respondents rated each of the 10 items in the SCL-10 on a four-point scale ranging from not at all (1) to extremely (4). We found an acceptable degree of internal consistency for the four-point scale in this sample (Cronbach's alpha: 0.87 , mean inter-item correlation: 0.43 , McDonald's omega coefficient for composite reliability: 0.939 ).

The average SCL-10 score was calculated by dividing the total score by the total number of items (range: 1.0-4.0) (Strand et al., 2003). An SCL-10 score of 1.85 has been proposed as the cut-off for predicting diagnosed mental disorders (Strand et al., 2003) and was used in this study. A composite binary mental health status variable was constructed by classifying respondents with scores below 1.85 as mentally healthy $(Y=0)$, and those with scores $\geq 1.85$ as mentally unhealthy $(Y=1)$. In addition to the binary variable, a separate continuous variable was constructed as the sum of the 10 items. The total sum of scores were linearly transformed from 0 to 1 , where 1 represents the worst mental health, and 0 represents perfect mental health (mean: 0.09, SD: 0.13 ), to facilitate comparison between the three measures of mental health, health, and well-being.

Health was assessed in the study questionnaire by the EQ5D generic measure of health-related quality of life. The EQ5D includes five health dimensions: mobility, self-care, usual activities, pain/discomfort, and anxiety/depression (The EuroQol Group., 1990). Each health dimension has three levels: (1) no problems, (2) some problems, and (3) unable or extreme problems. The sum of five indicators (range: 5-13) was divided in three groups (tertiles), with score ranges: 5 (healthy), 6 slightly unhealthy; implying one level down to "some problems" on only one of the five dimensions, and 7-13 (unhealthy). Those with the scores $7-13$ were classified as unhealthy $(Y=1)$, while those with the scores 5-6 were classified as relatively healthy $(Y=0)$. In addition to the binary variable, a separate continuous 
variable was constructed as the sum of the five items. The total sum of scores were then linearly transformed from 0 to 1 ; where 1 represents the worst health, and 0 represents perfect health (mean: 0.10, SD: 0.12).

Well-being was measured by the response to the first three items on the satisfaction with life scale (SWLS; Diener et al., 1985). These were: "In most ways my life is close to my ideal," "The conditions of my life are excellent," and "I am satisfied with my life." Respondents rated these statements using a 7point scale ranging from completely disagree (1) to completely agree (7). The sum of three indicators (range: 3-21) was divided in three groups (tertiles), with score ranges: 3-15 (low level of well-being), 16-18 (neither low nor high well-being), and 19-21 (high level of well-being). Those with scores 3-15 were classified as having a low level of well-being $(Y=1)$, while those with the scores 16-21 were classified as having a relatively high level of well-being $(Y=0)$. In addition to the binary variable, a separate continuous variable was constructed as the sum of the three items. The scores were inverted, so that a higher score represents lower well-being. The total sum of scores was linearly transformed from 0 to 1 ; where 1 represents the lowest wellbeing, and 0 represents the highest well-being (mean: 0.27, SD: $0.20)$.

The binary variables of mental health, health, and well-being were used for analyses with Shapley decomposition, chi-square tests, and Poisson regression models. The continuous variables (scale: $0-1$ ) were used for analyses with Shapley decomposition, quantile regression models, and analysis of variance [ANOVA with $F^{*}$ tests and Welch $(W)$ tests]. In addition, we performed all analysis with alternative cut-offs (see Online Supplementary Material).

\section{Childhood Traumatic Experiences (CTEs)}

Self-reported information on CTEs was collected by the question: "Have you over a long period experienced any of the following? (as a child)," followed by three types of traumatic experiences: (i) Being tormented, or threatened with violence; (ii) Being beaten, kicked, or the victim of other types of violence, and; (iii) Someone in your close family using alcohol or drugs in such a way that caused you worry. Respondents who ticked one or more of these responses were classified as exposed to psychological abuse, physical abuse, and substance abuse distress, respectively. To assess whether there is an additive effect of CTEs on mental health, health, and well-being, we constructed a separate variable of trauma frequency: $0=$ not exposed to any CTE (reference), 1 $=$ exposed to any one CTE, $2=$ exposed to any two CTEs, $3=$ exposed to all three CTEs.

\section{Mediators}

Social support and behavioral factors in adulthood were used as mediators. Social support was measured with indicators of instrumental/tangible support and emotional support. Instrumental or tangible support was measured as: "Do you have enough friends who can give you help and support when you need it?" (yes $=0$, no $=1$ ). Emotional support was measured as: "Do you have enough friends you can talk confidentially with?" (yes $=0$, no $=1$ ). Behavioral factors were measured as:
"Do you/did you smoke daily?" (yes, currently; yes, previously; never (reference)); and "How many units of alcohol (a beer, a glass of wine, or other alcoholic beverage) do you usually drink when you drink alcohol?" $1=1-4,2=5-6,3=7-9,4=10$ or more).

\section{Socio-Demographic Factors and Childhood Socioeconomic Status (Confounding Variables)}

The potential confounding variables: gender $(0=$ female, $1=$ male), age (range: $30-87$, mean: 57.52, standard deviation: 12.66 , standard error: 0.11), mother's education, father's education, and childhood financial conditions, were chosen based on a priori knowledge of the association between the exposures, mediators and outcomes under study (Hernán et al., 2002). Three indicators of CSES were used in this study; mother's education, father's education, and subjective assessment of childhood financial conditions. Respondents reported their mother's and father's education separately as: $1=$ primary and secondary school or similar (7-10 years of schooling), 2 = vocational school, $3=$ high school, $4=$ college or university (less than 4 years), and $5=$ college or university ( 4 years or more). The variable childhood financial conditions was measured retrospectively by the question: "How was your family's financial situation when you were a child?" on a 4 -point scale $(1=$ very good, $2=$ good, $3=$ difficult, 4 = very difficult).

\section{Statistical Analyses}

All analyses were performed using Stata version 13. The pattern of missingness was arbitrary in the dataset (data not shown). Assuming that the data is missing at random, 100 duplicate datasets were generated with multiple imputation (MI), to avoid sampling variability due to random iterations (StataCorp., 2013). In order to increase the predictive power of the imputation procedure, we included all indicators of socioeconomic status, mental health, health, and well-being in imputation models. A comparison between the complete-case and the imputed dataset is presented with proportions (\%) within each category of the variables (Tables 1, 2). Mean (standard error), median, and proportion of respondents in each category was calculated in the complete-case dataset and in the imputed dataset with MI (Tables 1, 2).

\section{Assessing the Relative Contribution of Socio-Demographic Factors, Childhood Socioeconomic Status and Childhood Traumatic Experiences to Social Support and Behavioral Factors in Adulthood}

We used Shapley (1953) decomposition of the dissimilarity index (Hoyos and Narayan, 2011) and $R^{2}$ (Huettner and Sunder, 2012) proposed by Shorrocks $(1982,2012)$, to examine the relative importance of socio-demographic factors, CSES and CTEs to social support and behavioral factors in adulthood (Table 3 ). 
TABLE 1 | General characteristics of the study sample in the complete-case dataset and the imputed dataset $(N=12,981)$.

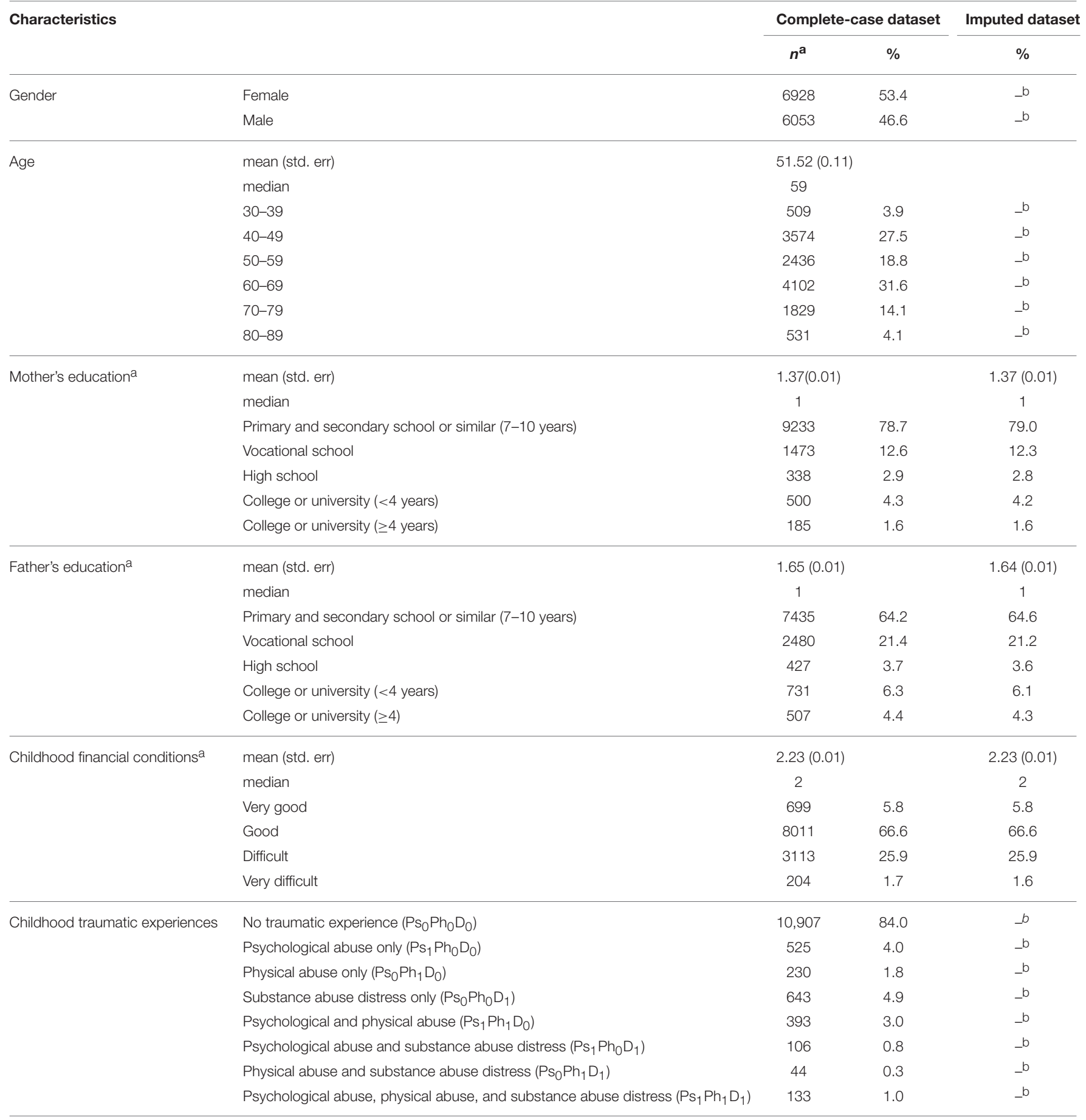

$P s_{0} P h_{0} D_{0}$ : Not exposed to psychological abuse, physical abuse and substance abuse distress in childhood. $P_{s_{1}} P h_{0} D_{0}:$ Exposed to psychological abuse but not physical abuse and substance abuse distress. $P S_{0} P h_{1} D_{0}$ : Exposed to physical abuse but not psychological abuse and substance abuse distress. $P_{s_{0}} P h_{0} D_{1}$ : Exposed to substance abuse distress, but not psychological abuse and physical abuse. PS $P_{1} P h_{1} D_{0}$ : Exposed to both psychological and physical abuse but not substance abuse distress. PS $P_{1} P h_{0} D_{1}$ : Exposed to both psychological abuse and substance abuse distress but not physical abuse. $P_{s_{0}} P h_{1} D_{1}$ : Exposed to both physical abuse and substance abuse distress but not psychological abuse. Ps $P_{1} h_{1} D_{1}$ : Exposed to psychological abuse, physical abuse, and substance abuse distress.

a The numbers do not add up to 12981 due to missing values.

${ }^{b}$ There were no missing values, so no imputations were made for these variables. 
TABLE 2 | Proportion (\%) of the mediating factors and health and well-being in the complete-case dataset, and in the imputed dataset with multiple imputation $(N=12,981)$.

\begin{tabular}{|c|c|c|c|}
\hline & & $\begin{array}{c}\text { Complete-case } \\
\text { dataset } \\
\%\end{array}$ & $\begin{array}{c}\text { Imputed } \\
\text { dataset } \\
\%\end{array}$ \\
\hline \multicolumn{4}{|l|}{ MEDIATORS } \\
\hline \multirow[t]{2}{*}{ Instrumental support ${ }^{\mathrm{a}}$} & Yes & 90.6 & 88.8 \\
\hline & No & 9.4 & 11.2 \\
\hline \multirow[t]{2}{*}{ Emotional support ${ }^{a}$} & Yes & 88.1 & 87.1 \\
\hline & No & 11.9 & 12.9 \\
\hline \multirow[t]{3}{*}{ Daily smoking b } & Never & 36.6 & 37.3 \\
\hline & Previous smoker & 43.1 & 42.3 \\
\hline & Current smoker & 20.3 & 20.4 \\
\hline \multirow[t]{4}{*}{ Alcohol use (units) ${ }^{b}$} & $1-4$ & 89.8 & 90.9 \\
\hline & $5-6$ & 7.4 & 6.8 \\
\hline & $7-9$ & 2.1 & 1.8 \\
\hline & 10 or more & 0.6 & 0.6 \\
\hline \multicolumn{4}{|c|}{ MENTAL HEALTH, HEALTH, AND WELL-BEING } \\
\hline \multirow[t]{3}{*}{ Mental health (SCL-10) } & Healthy & 91.9 & 90.7 \\
\hline & Unhealthy & 8.1 & 9.3 \\
\hline & mean (std. err) & 0.09 (0.001) & $0.10(0.001)$ \\
\hline \multirow[t]{3}{*}{ Health (EQ-5D) } & Healthy & 73.7 & 72.6 \\
\hline & Unhealthy & 26.3 & 27.4 \\
\hline & mean (std. err) & 0.09 (0.001) & $0.11(0.001)$ \\
\hline \multirow[t]{3}{*}{ Well-being (SWLS) } & High & 62.5 & 62.3 \\
\hline & Low & 37.6 & 37.7 \\
\hline & mean (std. err) & $0.27(0.002)$ & $0.28(0.002)$ \\
\hline
\end{tabular}

aSocial support factors were measured by instrumental and emotional support. Instrumental support: Do you have enough friends who can give you help and support when you need it? (yes, no); Emotional support: Do you have enough friends you can talk confidentially with? (yes, no)

${ }^{b}$ Behavioral factors were measured by two questions: Do you/did you smoke daily? (yes, now; yes, previously; never); How many units of alcohol (a beer, a glass of wine or a drink) do you usually drink when you drink alcohol? (1-4, 5-6, 7-9, 10, or more).

SCL-10: Mental health status was measured by the Hopkins Symptoms Check List-10 (SCL-10). EQ-5D: Health was assessed by the EQ-5D generic measure of health-related quality of life. SWLS: Well-being was measured by the satisfaction with life scale (SWLS).

\section{Assessing the Relative Contribution of Socio-Demographic Factors, Childhood Socioeconomic Status, Childhood Traumatic Experiences, Social Support, and Behavioral Factors to Adult Mental Health, Health, and Well-Being}

We used the Shapley decomposition of dissimilarity index (Shorrocks, 1982, 2012; Hoyos and Narayan, 2011) to examine the relative importance of socio-demographic factors, CSES, CTEs, social support, and behavioral factors to mental health, health, and well-being in adulthood. The Shapley decomposition
TABLE 3 | Relative contribution of structural conditions to social support and behavioral factors in adulthood.

\begin{tabular}{|c|c|c|c|c|}
\hline & \multicolumn{4}{|c|}{ Shapley decomposition (\% explained) } \\
\hline & $\begin{array}{l}\text { Instrumental } \\
\text { support }\end{array}$ & $\begin{array}{c}\text { Emotional } \\
\text { support }\end{array}$ & $\begin{array}{c}\text { Alcohol } \\
\text { use }\end{array}$ & Smoking \\
\hline Explanatory variables & $\%$ & $\%$ & $\%$ & $\%$ \\
\hline Gender & 0.17 & $35.73^{d}$ & $41.18^{d}$ & $9.75^{d}$ \\
\hline Age & $22.82^{d}$ & $8.26^{d}$ & $53.19^{d}$ & $1.76^{\mathrm{b}}$ \\
\hline Mother's education & 1.49 & 0.30 & $0.72^{d}$ & $27.01^{d}$ \\
\hline Father's education & $1.24^{d}$ & $0.86^{c}$ & 0.48 & $32.52^{d}$ \\
\hline Childhood financial conditions & $40.50^{d}$ & $29.26^{d}$ & $0.83^{b}$ & $7.83^{b}$ \\
\hline Psychological abuse & $20.04^{d}$ & $14.06^{d}$ & 0.30 & $1.98^{\mathrm{b}}$ \\
\hline Physical abuse & $8.72^{\mathrm{a}}$ & $8.35^{a}$ & $0.90^{b}$ & $15.90^{d}$ \\
\hline Substance abuse distress & $5.01^{\mathrm{C}}$ & 3.17 & $2.39^{d}$ & $3.26^{\mathrm{a}}$ \\
\hline
\end{tabular}

${ }^{a} P<0.1$.

${ }^{b} P<0.05$.

${ }^{c} P<0.01$.

${ }^{d} P<0.001$.

Instrumental support: Do you have enough friends who can give you help and support when you need it? (yes, no).

Emotional support: Do you have enough friends you can talk confidentially with? (yes, no). Alcohol use: How many units of alcohol (a beer, a glass of wine or a drink) do you usually drink when you drink alcohol? (1-4, 5-6, 7-9, 10 or more).

Smoking: Do you/did you smoke daily? [yes, now; yes, previously; never (ref)].

is based on the Shapley value concept in cooperative games to distribute among the players the surplus produced by a coalition of players among those players. The Shapley decomposition represents the extent to which an outcome varies (thereby, the inequality in mental health, health, or well-being) when a predictor is added to different pre-existing sets of predictors. The change in marginal probability of the outcome after adding a predictor gives the proportion of contribution influenced by that predictor. However, since the predictors may be correlated, the change in outcome obtained by adding a predictor depends on the initial set of predictors to which it was added. Therefore, to measure the relative contribution of a predictor $(\boldsymbol{x})$, the Shapley decomposition takes the average of all marginal impacts when the predictor $\boldsymbol{x}$ is added to all possible subsets of all other predictors considered. The total proportion (100\%) is then divided among the predictors based on their average marginal impacts (Tables 4, 5).

\section{Assessing the Relative Contribution of Socio-Demographic Factors, Childhood Socioeconomic Status, Childhood Traumatic Experiences, Social Support, Behavioral Factors and Mental Health to Health, and Well-Being}

To assess the relative importance of mental health to health, and that of mental health and health to well-being, we used Shapley decomposition of $R^{2}$ (Table 5). The continuous variables (scale: $0-1$ ) of mental health, health, and well-being were used (Table 5). 
TABLE 4 | Relative contribution of socio-demographic factors, childhood socioeconomic status, childhood traumatic experiences, social support and behavioral factors for mental health (SCL-10), health (EQ-5D), and subjective well-being (SWLS).

Shapley decomposition of dissimilarity

index (\% explained)

\begin{tabular}{|c|c|c|c|}
\hline & \\
\hline & $\begin{array}{c}\text { Mental health } \\
\text { (SCL-10) }\end{array}$ & $\begin{array}{l}\text { Health } \\
\text { (EQ-5D) }\end{array}$ & $\begin{array}{c}\text { Well-being } \\
\text { (SWLS) }\end{array}$ \\
\hline Explanatory variables & $\%$ & $\%$ & $\%$ \\
\hline Gender & $10.81^{d}$ & $21.32^{d}$ & $2.33^{d}$ \\
\hline Age & $2.56^{\mathrm{C}}$ & $11.08^{d}$ & 1.01 \\
\hline Mother's education & $0.93^{d}$ & $4.44^{d}$ & $2.27^{\mathrm{C}}$ \\
\hline Father's education & $0.61^{\mathrm{C}}$ & 2.68 & $1.30^{\mathrm{a}}$ \\
\hline Childhood financial conditions & $6.02^{d}$ & $10.60^{d}$ & $20.60^{d}$ \\
\hline Psychological abuse & $12.13^{d}$ & $7.01^{d}$ & $9.09^{d}$ \\
\hline Physical abuse & $5.30^{d}$ & $4.19^{c}$ & 3.63 \\
\hline Substance abuse distress & 2.73 & 1.72 & $4.72^{b}$ \\
\hline Instrumental support ${ }^{\mathrm{a}}$ & $24.16^{d}$ & $12.02^{d}$ & $19.95^{d}$ \\
\hline Emotional support ${ }^{\mathrm{a}}$ & $20.62^{d}$ & $10.87^{d}$ & $23.34^{d}$ \\
\hline Alcohol use (units) ${ }^{b}$ & $4.82^{d}$ & $2.21^{d}$ & $4.31^{d}$ \\
\hline \multicolumn{4}{|l|}{ Daily smoking ${ }^{\mathrm{b}}$} \\
\hline Never smoker (ref.) & Ref. & Ref. & Ref. \\
\hline Previous smoker & $0.85^{d}$ & $2.34^{d}$ & $0.55^{\mathrm{C}}$ \\
\hline Current smoker & $8.46^{d}$ & $9.50^{d}$ & $6.88^{d}$ \\
\hline Human Opportunity Index & 0.05 & 0.19 & 0.31 \\
\hline Dissimilarity index & 0.33 & 0.20 & 0.13 \\
\hline Penalty & 0.02 & 0.05 & 0.05 \\
\hline Coverage & 0.07 & 0.24 & 0.36 \\
\hline
\end{tabular}

${ }^{a} P<0.1$.

${ }^{b} P<0.05$

${ }^{c} P<0.01$

${ }^{d} P<0.001$

a Social support factors were measured by instrumental and emotional support. Instrumental support: Do you have enough friends who can give you help and support when you need it? (yes, no); Emotional support: Do you have enough friends you can talk confidentially with? (yes, no)

${ }^{b}$ Behavioral factors were measured by two questions: Do you/did you smoke daily? [yes, now; yes, previously; never (ref)]; How many units of alcohol (a beer, a glass of wine or a drink) do you usually drink when you drink alcohol? (1-4, 5-6, 7-9, 10 or more).

SCL-10: Mental health status was measured by the Hopkins Symptoms Check List-10 (SCL-10).

EQ-5D: Health was assessed by the EQ-5D generic measure of health-related quality of life.

SWLS: Well-being was measured by the satisfaction with life scale (SWLS).

\section{Independent Influence of Each Explanatory Variable on Mental Health, Health, and Well-Being}

The association between all the explanatory variables, and mental health, health, and well-being [continuous outcomes (scale: 0-1)] was assessed with quantile regression models (Table 6). All independent variables used in this study were included as predictors together in the model (adjusted for each other). Therefore, the estimates presented in Table 6 present the independent influence of each predictor (Table 6). In contrast to
TABLE 5 | Relative contribution of socio-demographic factors, childhood socioeconomic status, childhood traumatic experiences, social support, behavioral factors and mental health to health (EQ-5D), and subjective well-being (SWLS).

\begin{tabular}{|c|c|c|}
\hline & \multicolumn{2}{|c|}{$\begin{array}{l}\text { Shapley decomposition of } \\
\qquad R^{2}(\% \text { explained })\end{array}$} \\
\hline & Health (EQ-5D)g & Well-being (SWLS) ${ }^{h}$ \\
\hline Explanatory group of variables & $\%$ & $\%$ \\
\hline Socio-demographic factors ${ }^{a}$ & 8.45 & 0.54 \\
\hline Childhood socioeconomic status $^{\mathrm{b}}$ & 4.06 & 5.07 \\
\hline Childhood traumatic experiences $^{\mathrm{C}}$ & 3.31 & 3.29 \\
\hline Social support factors ${ }^{d}$ & 5.35 & 15.25 \\
\hline Behavioral factors ${ }^{e}$ & 3.22 & 1.63 \\
\hline Mental health ${ }^{\dagger}$ & 75.61 & 51.33 \\
\hline Health 9 & - & 22.89 \\
\hline Model $R^{2}$ & 0.30 & 0.25 \\
\hline$F$ & 253.79 & 171.73 \\
\hline$p$ & $<0.001$ & $<0.001$ \\
\hline \multicolumn{3}{|c|}{$\begin{array}{l}\text { aGender and age. } \\
\text { b Mother's education, father's education and childhood financial conditions. } \\
{ }^{c} \text { Psychological abuse, physical abuse and substance abuse distress. } \\
\text { dS Social support factors were measured by instrumental and emotional support. } \\
\text { Instrumental support: Do you have enough friends who can give you help and support } \\
\text { when you need it? (yes, no); Emotional support: Do you have enough friends you can talk } \\
\text { confidentially with? (yes, no). } \\
\text { eBehavioral factors were measured by two questions: Do you/did you smoke daily? (yes, } \\
\text { now; yes, previously; never (ref)); How many units of alcohol (a beer, a glass of wine or a } \\
\text { drink) do you usually drink when you drink alcohol? (1-4, } 5-6,7-9,10 \text { or more). } \\
\text { fSCL-10: Mental health status was measured by the Hopkins Symptoms Check List-10 } \\
\text { (SCL-10); scale (0-1), where } 0 \text { represents perfect mental health, and } 1 \text { represents worst } \\
\text { mental health. } \\
{ }^{g} E Q-5 D: \text { Health was assessed by the EQ-5D generic measure of health-related quality of } \\
\text { life; scale (0-1), where } 0 \text { represents perfect health, and } 1 \text { represents worst health. } \\
\text { hSWLS: Well-being was measured by the satisfaction with life scale (SWLS); scale (0-1), } \\
\text { where } 0 \text { represents highest well-being, and } 1 \text { represents lowest well-being. }\end{array}$} \\
\hline
\end{tabular}

the ordinary least square (OLS) model, quantile regression uses the conditional median function $Q_{q}\left(y \mid x_{i \ldots k}\right)$, where median is the 50th percentile. The quantile $q \in(0,1)$ is that $y$ splits the data into proportions $q$ below and $1-q$ above: $F\left(y_{q}\right)=q$ and $y_{q}=F^{-1}$ (q): for the median, $q=0.5$. The Huber sandwich estimator was used for the variance-covariance matrix, which does not assume that the errors are independently and identically distributed. The quantile regression model minimizes model prediction error $\sum i$ $\left|e_{i}\right|$, in contrast to $\sum i\left|e_{i}^{2}\right|$ in the OLS model, and is therefore more robust in terms of deviation from a parametric distribution of errors.

\section{Association between Childhood Traumatic Experiences, and Social Support and Behavioral Factors in Adulthood}

The association between the different combinations of CTEs, and social support and behavioral factors was assessed with crosstabulation with chi-square tests, $F^{*}$ test and Welch $(W)$ test (Table 7). 
TABLE 6 | Independent association between all explanatory variables, and mental health (SCL-10), health (EQ-5d), and subjective well-being (SWLS) with quantile regression model $(N=12,981)$.

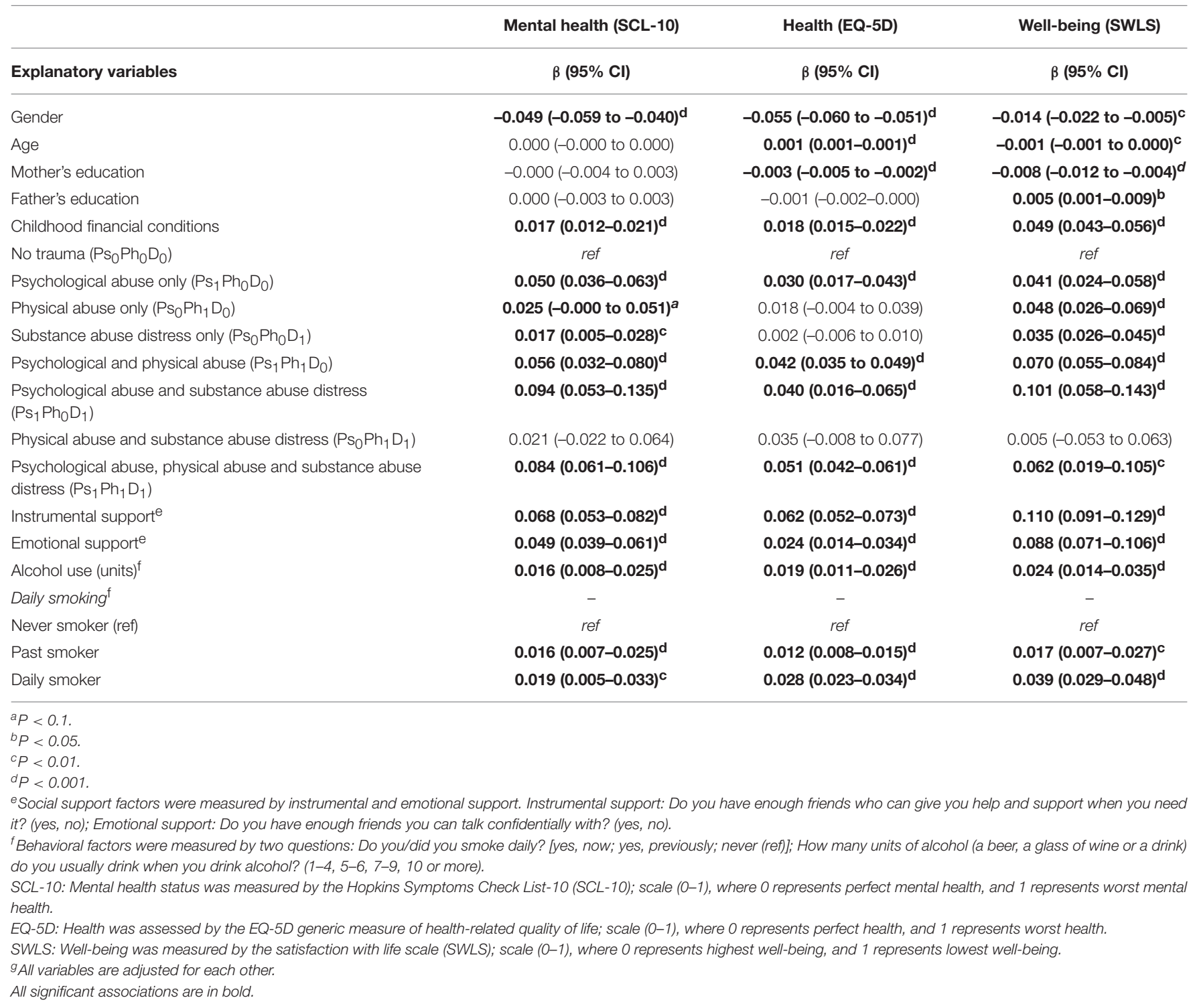

\section{Association between Childhood Traumatic Experiences and Mental Health, Health, and Well-Being in Adulthood}

The crude association between CTEs and mental health, health, and well-being in adulthood was assessed with linear regression (Figure 1), $F^{*}$ tests, Welch $(W)$ tests (Table 7), and crosstabulation with chi-square tests (Table 7). The $F^{*}$ test is a modification of the standard $F$-test that is more robust to violations of the homogeneity of variance assumption (Wilcox et al., 1986). Similarly, Welch $(W)$ test is more robust to violations of homogeneity of variances (Welch, 1947; Wilcox et al., 1986). To assess the linear trend, the trauma frequency variable was modeled as a continuous variable in the quantile regression models [using continuous outcomes (scale: 0-1)] (Table 8). Furthermore, we assessed if there was a significant difference between the three CTEs with multiple comparisons (Table 8).
The independent influence of CTEs (adjusted for covariates, and mediators) on mental health, health, and well-being was assessed with quantile regression models [using continuous outcomes (scale: 0-1)] (Table 6), and Poisson regression models (using binary outcomes) (Tables 11, 12).

\section{Association between Social Support and Behavioral Factors, and Mental Health, Health, and Well-Being in Adulthood}

The crude association between social support and behavioral factors, and mental health, health, and well-being was assessed with cross-tabulation with chi-square tests (using binary outcomes) (Table 9). The independent influence (adjusted for covariates) of social support and behavioral factors on mental health, health, and well-being was assessed with quantile regression models [using continuous outcomes (scale: $0-1$ )] 


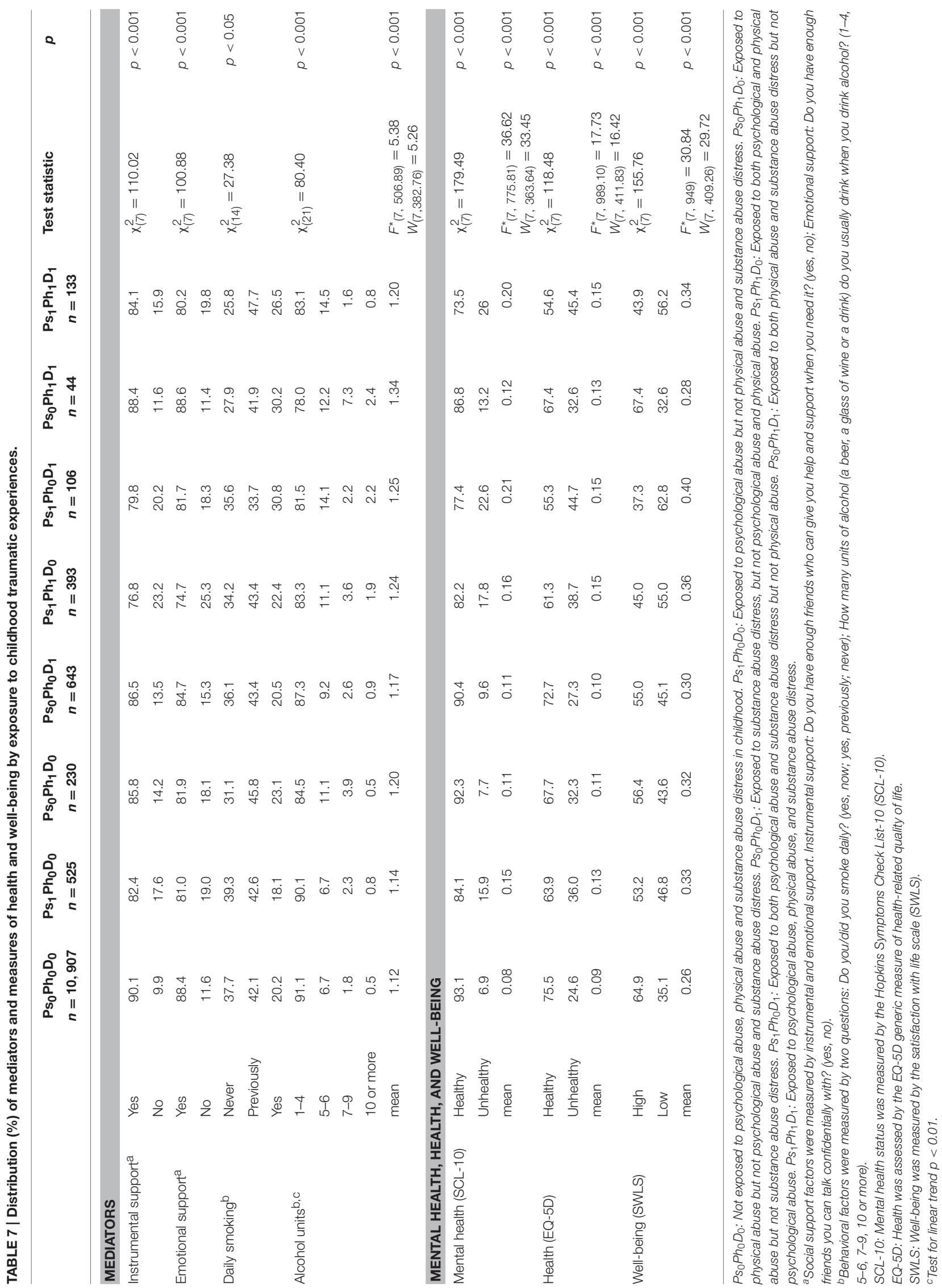




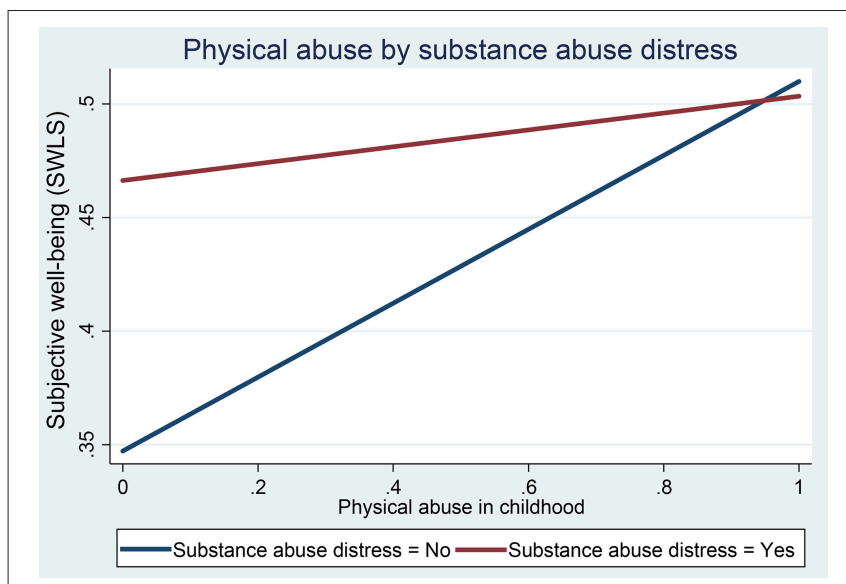

FIGURE 1 | Effect of physical abuse on well-being (OLS model) by substance abuse distress in childhood.

(Table 6) and Poisson regression models (using binary outcomes) (Table 10).

\section{Assessing Direct and Indirect Effect (Through Social Support and Behavioral Factors in Adulthood) of Childhood Traumatic Experiences on Mental Health, Health, and Well-Being}

The binary variables of mental health, health, and well-being were used for mediation analyses. The three types of CTEs were tested for pairwise multiplicative interaction between them with logistic and Poisson regression models. In addition, all independent variables were tested for pairwise multiplicative interactions with the CTEs combinations, by logistic and Poisson regression models.

As the outcomes were binary, we used the following model to fit the data, in which $y=$ health or well-being outcome; ps $=$ psychological abuse in childhood; ph $=$ physical abuse in childhood; $\mathrm{d}=$ substance abuse distress in childhood; and $\mathrm{c}=$ covariates:

$$
\begin{array}{r}
\log \{P(Y=1 \mid p s, p h, d, c)\}=\beta_{0}+\beta_{1} p s+\beta_{2} p h \\
+\beta_{3} d+\beta_{4} p s * p h+\beta_{5} p s * d+\beta_{6} p h * d \\
+\beta_{7} p s * p h * d+\beta_{8} c
\end{array}
$$

A statistically significant multiplicative interaction $(p<0.05)$ was observed between the three types of CTEs (see Figure 1). Therefore, we estimated the effect of seven combinations of these CTEs, compared to no traumatic experience, as $\mathrm{Ps}_{\mathrm{i}} \mathrm{Ph}_{\mathrm{i}} \mathrm{D}_{\mathrm{k}}$, where $i, j$, and $k$ represent the values 0 (not exposed) or 1 (exposed) for the three types of CTEs:

- $\mathrm{Ps}_{0} \mathrm{Ph}_{0} \mathrm{D}_{0:}$ Not exposed to any of the three CTEs $(n=10,907)$ (reference category);

- $\mathrm{Ps}_{1} \mathrm{Ph}_{0} \mathrm{D}_{0}$ : Exposed to psychological abuse, but not physical abuse or substance abuse distress $(n=525)$;
- $\mathrm{Ps}_{0} \mathrm{Ph}_{1} \mathrm{D}_{0}$ : Exposed to physical abuse, but not psychological abuse or substance abuse distress $(n=230)$;

- $\mathrm{Ps}_{0} \mathrm{Ph}_{0} \mathrm{D}_{1}$ : Exposed to substance abuse distress, but not psychological abuse or physical abuse $(n=643)$;

- $\mathrm{Ps}_{1} \mathrm{Ph}_{1} \mathrm{D}_{0}$ : Exposed to both psychological and physical abuse, but not substance abuse distress $(n=393)$;

- $\mathrm{Ps}_{1} \mathrm{Ph}_{0} \mathrm{D}_{1}$ : Exposed to both psychological abuse and substance abuse distress, but not physical abuse $(n=106)$;

- $\mathrm{Ps}_{0} \mathrm{Ph}_{1} \mathrm{D}_{1}$ : Exposed to both physical abuse and substance abuse distress, but not psychological abuse $(n=44)$;

- $\mathrm{Ps}_{1} \mathrm{Ph}_{1} \mathrm{D}_{1}$ : Exposed to all three CTEs $(n=133)$.

Each combination of CTEs constituted a separate exposure in the analyses. Unadjusted estimates, and estimates adjusted for potential confounding variables are presented (Tables 11, 12). The estimation strategy for assessing mediation was based on prior theory and the Causal Steps method (Judd and Kenny, 1981; Baron and Kenny, 1986). We used the 'difference method' approach (Wright, 1934; Judd and Kenny, 1981; Clogg et al., 1992) to assess mediation. An important assumption of assessing mediation is that there is no exposuremediator multiplicative interaction (Clogg et al., 1992; Robins and Greenland, 1992; Have et al., 2004; Kaufman et al., 2004; Martinussen, 2009; Sheikh et al., 2014). Other assumptions for assessing mediation with multiple mediators include that there is no multiplicative interaction between mediators, or between mediators and covariates. Moreover, when the outcome is not rare, odds ratios are not suitable for assessing mediation (Pearl, 2012; Sheikh et al., 2014), as the direct effect is overestimated, and the indirect effect is underestimated (Jiang and VanderWeele, 2015) due to the property of non-collapsibility (Miettinen and Cook, 1981; Greenland, 1987; Greenland et al., 1999; Pang et al., 2013). Therefore, Poisson regression analysis (RR and 95\% CIs) with robust error variance (Barros and Hirakata, 2003; Zou, 2004) was used to estimate the total and direct effect of CTEs on mental health, health, and wellbeing. Mediators were included in the models to assess the indirect effect in the form of proportion of mediated effect (\% attenuation) (Susser, 1973; Szklo and Nieto, 2000). We calculated 95\% CIs for indirect effects using a bias-corrected accelerated bootstrap method (Carpenter and Bithell, 2000) with 2000 re-samplings. The \% attenuation (indirect effect) was not estimated when the RR (of total effect or direct effect) was less than 1.00, or when there was no reduction in the $R R_{\text {Total Effect }}$ after including the mediators in the model (Tables 11, 12). Mediation was assessed in both the complete-case dataset (excluding missing) (Table 11), and the imputed dataset with MI (Table 12).

\section{RESULTS}

Tables 1, 2 presents the general characteristics of the study sample. The numbers for mother's education, father's education, and childhood financial conditions do not add 
TABLE 8 | Association between childhood traumatic experiences and mental health (SCL-10), health (EQ-5D), and subjective well-being (SWLS) with quantile regression models $(N=12,981)$.

\begin{tabular}{|c|c|c|c|c|}
\hline & & \multicolumn{3}{|c|}{ Imputed dataset with multiple imputation $(n=12,981)$} \\
\hline & & Mental health (SCL-10) & Health (EQ-5D) & Well-being (SWLS) \\
\hline Childhood traumatic experiences & $n$ & $\beta(95 \% \mathrm{Cl})$ & $\beta(95 \% \mathrm{Cl})$ & $\beta(95 \% \mathrm{Cl})$ \\
\hline Trauma frequency (reference: not exposed) ${ }^{\mathrm{e}, \mathrm{i}}$ & 10,907 & Ref & Ref & Ref \\
\hline Exposed to any one traumatic experience ${ }^{e, i}$ & 525 & $0.03(0.01-0.05)^{d}$ & $0.03(0.02-0.04)^{d}$ & $0.06(0.05-0.06)^{d}$ \\
\hline Exposed to any two traumatic experiences ${ }^{e, i}$ & 1416 & $0.03(0.03-0.11)^{d}$ & $0.03(0.02-0.03)^{d}$ & $0.06(0.05-0.06)^{d}$ \\
\hline Exposed to all three traumatic experiences ${ }^{e}, i$ & 133 & $0.07(0.03-0.11)^{d}$ & $0.06(0.04-0.08)^{d}$ & $0.06(0.01-0.10)^{b}$ \\
\hline Psychological abuse vs. physical abuse (ref $)^{h}$ & 1431 & $0.00(-0.02-0.02)$ & $-0.01(-0.02-0.00)$ & $0.00(-0.02-0.02)$ \\
\hline Psychological abuse vs. substance abuse distress (ref) 9 & 1844 & $0.03(0.02-0.05)^{d}$ & $0.01(-0.01-0.03)$ & $0.00(-0.02-0.02)$ \\
\hline Physical abuse vs. substance abuse distress (ref) ${ }^{f}$ & 1549 & $-0.00(-0.02-0.01)$ & $-0.00(-0.02-0.02)$ & $-0.00(-0.02-0.02)$ \\
\hline $\begin{array}{l}\text { Psychological abuse and physical abuse vs. substance abuse } \\
\text { distress }(\text { ref) })^{e}\end{array}$ & 1319 & $0.04(0.01-0.06)^{c}$ & $-0.00(-0.02-0.02)$ & $0.02(-0.02-0.06)$ \\
\hline Psychological abuse and distress vs. physical abuse (ref)e & 906 & $0.04(-0.00-0.09)^{a}$ & $-0.00(-0.02-0.02)$ & $0.06(-0.00-0.11)^{a}$ \\
\hline Physical abuse and distress vs. psychological abuse (ref) ${ }^{e}$ & 1201 & $-0.02(-0.07-0.04)$ & $-0.01(-0.06-0.04)$ & $-0.06(-0.12-0.01)^{a}$ \\
\hline $\begin{array}{l}\text { All three traumatic experiences vs. psychological abuse and } \\
\text { physical abuse only (ref)e,j }\end{array}$ & 526 & $0.03(-0.02-0.07)$ & $0.02(-0.01-0.05)$ & $0.00(-0.05-0.05)$ \\
\hline $\begin{array}{l}\text { All three traumatic experiences vs. psychological abuse and } \\
\text { substance abuse distress only (ref) })^{\mathrm{e}, \mathrm{k}}\end{array}$ & 239 & $0.01(-0.04-0.07)$ & $0.03(-0.02-0.08)$ & $0.00(-0.06-0.06)$ \\
\hline $\begin{array}{l}\text { All three traumatic experiences vs. physical abuse and } \\
\text { substance abuse distress only (ref) })^{e, I}\end{array}$ & 177 & $0.08(0.01-0.14)^{b}$ & $0.04(-0.00-0.09)^{a}$ & $0.06(-0.01-0.13)$ \\
\hline
\end{tabular}

${ }^{a} P<0.1$

${ }^{b} P<0.05$

${ }^{c} P<0.01$.

${ }^{d} P<0.001$

${ }^{e}$ Adjusted for confounding variables.

${ }^{f}$ Adjusted for confounding variables and psychological abuse.

${ }^{g}$ Adjusted for confounding variables and physical abuse.

${ }^{h}$ Adjusted for confounding variables and substance abuse distress.

iTest for linear trend $p<0.001$.

${ }^{j} P s_{1} P h_{1} D_{1}$ vs. $P s_{1} P h_{1} D_{0}$ (ref).

${ }^{k} P s_{1} P h_{1} D_{1}$ vs. $P s_{1} P h_{0} D_{1}$ (ref).

${ }^{\prime} P s_{1} P h_{1} D_{1} v s$. $P s_{0} P h_{1} D_{1}$ (ref).

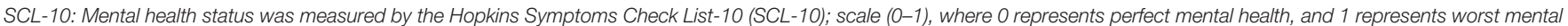
health. EQ-5D: Health was assessed by the EQ-5D generic measure of health-related quality of life; scale (0-1), where 0 represents perfect health, and 1 represents worst health. SWLS: Well-being was measured by the satisfaction with life scale (SWLS); scale (0-1), where 0 represents highest well-being, and 1 represents lowest well-being.

All significant associations are in bold.

up to 12,981 due to missing values. Proportions (\%) of respondents in the imputed dataset are also presented (Tables 1, 2). The numbers and proportions (\%) of the combinations of childhood traumatic experiences show that there is a considerable overlap between the three exposures (Table 1).

The majority $(77.9 \%)$ of the respondents were between 40 and 69 years of age, reported primary and secondary school or similar as mother's (78.7\%) and father's education (64.2\%), and reported having good financial conditions in childhood (66.6\%) (Table 1). The distributions of variables were similar in the complete-case dataset (excluding those with missing values) and the imputed dataset with MI (Tables 1, 2).
Relative Contribution of Socio-Demographic Factors, Childhood Socioeconomic Status, Childhood Traumatic Experiences to Social Support, and Behavioral Factors in Adulthood

Table 3 presents the average marginal contribution of all explanatory variables to social support and behavioral factors. The Shapley decomposition shows that among all the variables considered, childhood financial conditions was most important to instrumental support (40.50\%), gender was most important to emotional support (35.73\%), age was most important to alcohol use $(53.19 \%)$, while father's education was most important to smoking (32.52\%). 
TABLE 9 | Distribution (\%) of mediators by mental health (SCL-10), health (EQ-5D), and subjective well-being (SWLS).

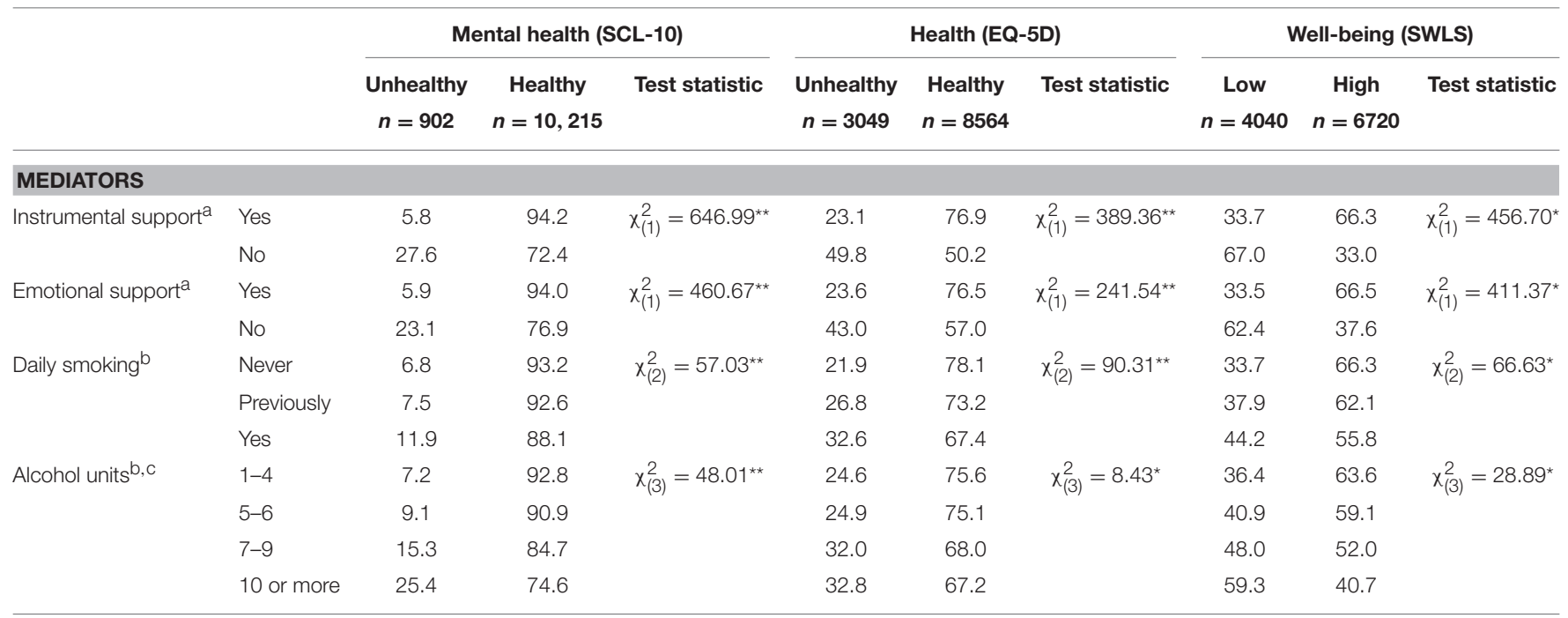

${ }^{*} p<0.05$

${ }^{* *} p<0.001$.

a Social support factors were measured by instrumental and emotional support. Instrumental support: Do you have enough friends who can give you help and support when you need it? (yes, no); Emotional support: Do you have enough friends you can talk confidentially with? (yes, no).

${ }^{b}$ Behavioral factors were measured by two questions: Do you/did you smoke daily? (yes, now; yes, previously; never); How many units of alcohol (a beer, a glass of wine or a drink) do you usually drink when you drink alcohol? (1-4, 5-6, 7-9, 10 or more).

SCL-10: Mental health status was measured by the Hopkins Symptoms Check List-10 (SCL-10).

$E Q-5 D$ : Health was assessed by the EQ-5D generic measure of health-related quality of life.

SWLS: Well-being was measured by the satisfaction with life scale (SWLS).

${ }^{c}$ Test for linear trend $p<0.001$.

However, when the socio-demographic variables (gender, age) and CSES (mother's education, father's education and childhood financial conditions) were considered together, CSES explained most variation in instrumental support (43.23\%), and smoking (67.36\%), while socio-demographic variables explained most variation in emotional support (43.99\%) and alcohol use (94.37\%) (Table 3).

\section{Relative Contribution of Socio-Demographic Factors, Childhood Socioeconomic Status, Childhood Traumatic Experiences, Social Support, and Behavioral Factors to Mental Health, Health, and Well-Being}

Table 4 presents the average marginal contribution of all explanatory variables used in this study. The Shapley decomposition shows that among all the variables considered, instrumental support $(24.16 \%)$ explained most of the variation in mental health, while gender (21.32\%) explained most of the variation in health, and emotional support (23.34\%) explained most of the variation in well-being.

Among all the indicators of childhood adversities, psychological abuse (12.13\%) was most important for mental health in adulthood, followed by childhood financial conditions (6.02\%), physical abuse (5.30\%), substance abuse distress $(2.73 \%)$, mother's education (0.93\%), and father's education $(0.61 \%)$. While for health in adulthood, childhood financial conditions (10.60\%) was most important, followed by psychological abuse (7.01\%), mother's education (4.44\%), physical abuse (4.19\%), father's education (2.68\%), and substance abuse distress (1.72\%). Furthermore, for well-being, childhood financial conditions $(20.60 \%)$ was most important, followed by psychological abuse (9.09\%), substance abuse distress (4.72\%), physical abuse (3.63\%), mother's education (2.27\%), and father's education $(1.30 \%)$. However, when the CTEs were considered together, they were relatively more important for mental health than the three indicators of CSES (20.16\% for CTEs vs. $7.56 \%$ for CSES). The three indicators of CSES were relatively more important for health $(17.72 \% v$ s. $12.92 \%)$ and well-being $(24.17 \%$ vs. 17.44\%) than CTEs (Table 4).

Similarly, if both the social support factors are considered together, they explain most of the variation in mental health (44.78\%), health (22.89\%) and well-being (43.29\%). Among the indicators of social support and behavioral factors, instrumental support was most important for mental health $(24.16 \%)$ and health (12.02\%), followed by emotional support and current smoking. While for well-being, emotional support (23.34\%) was most important, followed by instrumental support (19.95\%) and current smoking $(6.88 \%)$. 
TABLE 10 | Association between mediators and mental health (SCL-10), health (EQ-5D), and subjective well-being (SWLS).

\begin{tabular}{|c|c|c|c|c|c|}
\hline \multirow[t]{3}{*}{ Mediators ${ }^{e, f}$} & & \multicolumn{2}{|c|}{ Complete-case analysis (excluding missing) } & \multicolumn{2}{|c|}{ Imputed dataset with multiple imputation $(n=12,981)$} \\
\hline & & Unadjusted & Adjusted & Unadjusted & Adjusted \\
\hline & & RR $(95 \% \mathrm{Cl})$ & RR (95\% Cl) & RR (95\% Cl) & RR (95\% Cl) \\
\hline \multicolumn{6}{|c|}{ MENTAL HEALTH (SCL-10) } \\
\hline Instrumental support ${ }^{\mathrm{e}}$ & $\mathrm{No}^{\mathrm{g}}$ & $4.76(4.21-5.39)^{d}$ & $2.53(1.96-3.28)^{d}$ & $4.57(4.10-5.10)^{d}$ & $2.49(2.08-2.99)^{d}$ \\
\hline Emotional support ${ }^{e}$ & Nog & $3.86(3.41-4.39)^{d}$ & $1.88(1.46-2.44)^{d}$ & $3.73(3.34-4.17)^{d}$ & $1.87(1.57-2.24)^{d}$ \\
\hline \multirow[t]{3}{*}{ Alcohol use (units) $)^{f, h, k}$} & $5-6^{h}$ & $1.27(0.99-1.61)^{a}$ & $1.23(0.93-1.61)$ & $1.13(0.91-1.41)$ & $1.25(1.01-1.56)^{b}$ \\
\hline & $7-9^{h}$ & $2.12(1.52-2.96)^{d}$ & $1.98(1.41-2.77)^{d}$ & $1.75(1.28-2.40)^{d}$ & $1.92(1.42-2.58)^{\mathrm{d}}$ \\
\hline & 10 or more $^{\mathrm{h}}$ & $3.53(2.27-5.50)^{\mathrm{d}}$ & $3.26(2.17-4.89)^{d}$ & $2.92(1.95-4.37)^{d}$ & $2.54(1.69-3.85)^{d}$ \\
\hline \multirow[t]{2}{*}{ Daily smoking ${ }^{f, i}$} & Previous smokeri & $1.10(0.94-1.28)$ & $1.18(0.98-1.42)^{a}$ & $1.11(0.97-1.27)$ & 1.09 (0.96-1.24) \\
\hline & Current smoker & $1.77(1.51-2.08)^{d}$ & $1.63(1.34-1.99)^{d}$ & $1.76(1.53-2.02)^{d}$ & $1.54(1.34-1.76)^{d}$ \\
\hline \multicolumn{6}{|l|}{ HEALTH (EQ-5D) } \\
\hline Instrumental support ${ }^{\mathrm{e}}$ & Nog & $2.15(2.01-2.31)^{d}$ & $1.46(1.29-1.64)^{d}$ & $2.12(1.99-2.26)^{d}$ & $1.52(1.38-1.67)^{d}$ \\
\hline Emotional support ${ }^{\mathrm{e}}$ & Nog & $1.82(1.70-1.96)^{d}$ & $1.39(1.24-1.57)^{d}$ & $1.80(1.69-1.92)^{d}$ & $1.29(1.18-1.42)^{d}$ \\
\hline \multirow[t]{3}{*}{ Alcohol use (units) $)^{f, h, k}$} & $5-6^{h}$ & $1.02(0.90-1.16)$ & $1.25(1.09-1.44)^{d}$ & $0.96(0.85-1.09)$ & $1.22(1.08-1.38)^{\mathrm{C}}$ \\
\hline & $7-9^{h}$ & $1.31(1.07-1.61)^{\mathrm{C}}$ & $1.72(1.38-2.14)^{d}$ & $1.24(1.02-1.50)^{b}$ & $1.68(1.39-2.03)^{d}$ \\
\hline & 10 or more $^{h}$ & $1.35(0.94-1.93)$ & $1.64(1.12-2.41)^{c}$ & $1.21(0.86-1.72)$ & $1.49(1.05-2.12)^{b}$ \\
\hline \multirow[t]{2}{*}{ Daily smoking ${ }^{f, i}$} & Previous smokeri & $1.10(0.94-1.28)$ & $1.24(1.13-1.35)^{d}$ & $1.19(1.11-1.27)^{\mathrm{d}}$ & $1.15(1.08-1.23)^{\mathrm{d}}$ \\
\hline & Current smokeri & $1.77(1.51-2.08)^{d}$ & $1.49(1.35-1.64)^{d}$ & $1.44(1.34-1.56)^{d}$ & $1.38(1.28-1.49)^{d}$ \\
\hline \multicolumn{6}{|l|}{ WELL-BEING (SWLS) } \\
\hline Instrumental support ${ }^{\mathrm{e}}$ & Nog & $1.99(1.89-2.10)^{d}$ & $1.39(1.28-1.52)^{d}$ & $1.92(1.83-2.01)^{d}$ & $1.40(1.30-1.51)^{\mathrm{d}}$ \\
\hline Emotional support ${ }^{e}$ & Nog & $1.86(1.77-1.96)^{d}$ & $1.44(1.33-1.57)^{d}$ & $1.83(1.75-1.92)^{d}$ & $1.40(1.30-1.50)^{d}$ \\
\hline \multirow[t]{3}{*}{ Alcohol use (units) ${ }^{f, h, k}$} & $5-6^{h}$ & $1.12(1.02-1.23)^{b}$ & $1.12(1.01-1.23)^{b}$ & $1.12(1.03-1.22)^{b}$ & $1.11(1.01-1.21)^{b}$ \\
\hline & $7-9^{h}$ & $1.32(1.14-1.53)^{\mathrm{d}}$ & $1.33(1.15-1.55)^{\mathrm{d}}$ & $1.27(1.09-1.47)^{\mathrm{C}}$ & $1.24(1.07-1.43)^{\mathrm{C}}$ \\
\hline & 10 or more $^{h}$ & $1.63(1.32-2.02)^{d}$ & $1.48(1.17-1.86)^{d}$ & $1.56(1.26-1.93)^{\mathrm{d}}$ & $1.43(1.15-1.76)^{d}$ \\
\hline \multirow[t]{2}{*}{ Daily smoking ${ }^{f, i}$} & Previous smokeri & $1.12(1.06-1.19)^{d}$ & $1.08(1.02-1.15)^{b}$ & $1.10(1.05-1.17)^{d}$ & $1.07(1.02-1.13)^{\mathrm{C}}$ \\
\hline & Current smokeri & $1.31(1.23-1.40)^{\mathrm{d}}$ & $1.22(1.13-1.31)^{\mathrm{d}}$ & $1.29(1.21-1.37)^{\mathrm{d}}$ & $1.22(1.14-1.29)^{\mathrm{d}}$ \\
\hline
\end{tabular}

${ }^{a} P<0.1$.

${ }^{b} P<0.05$

${ }^{c} P<0.01$.

${ }^{d} P<0.001$

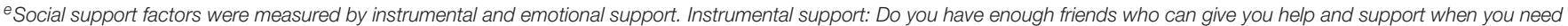
it? (yes, no); Emotional support: Do you have enough friends you can talk confidentially with? (yes, no).

${ }^{f}$ Behavioral factors were measured by two questions: Do you/did you smoke daily? (yes, now; yes, previously; never); How many units of alcohol (a beer, a glass of wine or a drink) do you usually drink when you drink alcohol? (1-4, 5-6, 7-9, 10 or more).

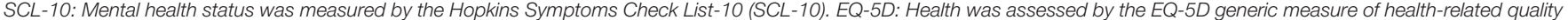
of life. SWLS: Well-being was measured by the satisfaction with life scale (SWLS).

gReference: Yes.

${ }^{h}$ Reference: $1-4$ units.

${ }^{i}$ Reference: Never.

${ }^{j}$ Adjusted for childhood traumatic experiences, confounding variables and other mediators.

kTest for linear trend $p<0.001$.

All significant associations are in bold.

The binary outcomes of mental health, health, and well-being were used.

\section{Relative Contribution of}

\section{Socio-Demographic Factors, Childhood Socioeconomic Status, Childhood Traumatic Experiences, Social Support, Behavioral Factors and Mental Health to Health, and Well-Being}

Table 5 shows that when the relative importance of mental health is taken into consideration for health, it explained most variation in health (75.61\%), followed by socio-demographic factors $(8.45 \%)$, social support factors (5.35\%), CSES (4.06\%),
CTEs (3.31\%), and behavioral factors (3.22\%). However, for well-being, mental health explained most variation (51.33\%), followed by health $(22.89 \%)$, social support factors $(15.25 \%)$, CSES (5.07\%), CTEs (3.29\%), behavioral factors (1.63\%) and socio-demographic factors (0.54\%).

\section{Independent Influence of Each Explanatory Variable on Mental Health, Health, and Well-Being}

All the independent variables used in this study were included as predictors in the quantile regression model (adjusted for 
TABLE 11 | Effect of exposure to childhood traumatic experiences on mental health (SCL-10), health (EQ-5D), and subjective well-being (SWLS).

\begin{tabular}{|c|c|c|c|c|}
\hline & Crude effects & Total effects & Direct effects & $\begin{array}{l}\text { Proportion mediated } \\
\text { (Indirect effects) }\end{array}$ \\
\hline & Unadjusted & $\begin{array}{l}\text { Adjusted for } \\
\text { confounding variables }^{c}\end{array}$ & $\begin{array}{l}\text { Adjusted for confounding } \\
\text { variables }^{c} \text { and mediators } \\
\text { a,b }\end{array}$ & \\
\hline Childhood traumatic experiences (CTEs) & RR $(95 \% \mathrm{Cl})$ & RR (95\% Cl) & RR (95\% Cl) & $\%$ attentuation ${ }^{\mathrm{d}}(95 \% \mathrm{Cl})$ \\
\hline \multicolumn{5}{|l|}{ MENTAL HEALTH (SCL-10) $n=8547$} \\
\hline No trauma $\left(\mathrm{Ps}_{0} \mathrm{Ph}_{0} \mathrm{D}_{0}\right)$ & 1.00 & 1.00 & 1.00 & Ref \\
\hline Psychological abuse only $\left(\mathrm{Ps}_{1} \mathrm{Ph}_{0} \mathrm{D}_{0}\right)$ & $2.29(1.84-2.87)$ & $2.19(1.67-2.87)$ & $1.92(1.49-2.47)$ & $22.88(2.96-40.26)$ \\
\hline Physical abuse only $\left(\mathrm{Ps}_{0} \mathrm{Ph}_{1} \mathrm{D}_{0}\right)$ & $1.11(0.69-1.80)$ & $1.10(0.61-1.97)$ & $1.08(0.61-1.92)$ & 17.82(-42.84-4455.85) \\
\hline Substance abuse distress only $\left(\mathrm{Ps}_{0} \mathrm{Ph}_{0} \mathrm{D}_{1}\right)$ & $1.39(1.07-1-82)$ & $1.02(0.73-1.43)$ & $0.93(0.68-1.29)$ & - \\
\hline Psychological and physical abuse $\left(\mathrm{Ps}_{1} \mathrm{Ph}_{1} \mathrm{D}_{0}\right)$ & $2.58(2.03-3.28)$ & $2.69(2.03-3.58)$ & $1.99(1.52-2.60)$ & $41.60(24.67-56.27)$ \\
\hline $\begin{array}{l}\text { Psychological abuse and substance abuse distress } \\
\left(\mathrm{Ps}_{1} \mathrm{Ph}_{0} \mathrm{D}_{1}\right)\end{array}$ & $3.27(2.23-4.80)$ & $2.14(1.23-3.73)$ & $1.51(0.89-2.56)$ & $54.97(1.38-153.99)$ \\
\hline Physical abuse and substance abuse distress & $1.91(0.84-4.33)$ & $2.22(0.88-5.57)$ & $2.37(0.95-5.95)$ & - \\
\hline
\end{tabular}

$\left(\mathrm{Ps}_{0} \mathrm{Ph}_{1} \mathrm{D}_{1}\right)$

Psychological abuse, physical abuse and substance

$3.85(2.81-5.27)$

$3.72(2.67-5.20)$

3.10(2.20-4.35)

23.01(-1.08-42.94)

abuse distress $\left(\mathrm{Ps}_{1} \mathrm{Ph}_{1} \mathrm{D}_{1}\right)$

\section{HEALTH (EQ-5D) $\boldsymbol{n}=\mathbf{9 3 1 2}$}

No trauma $\left(\mathrm{Ps}_{0} \mathrm{Ph}_{0} \mathrm{D}_{0}\right)$

Psychological abuse only $\left(\mathrm{Ps}_{1} \mathrm{Ph}_{0} \mathrm{D}_{0}\right)$

Physical abuse only $\left(\mathrm{Ps}_{0} \mathrm{Ph}_{1} \mathrm{D}_{0}\right)$

Substance abuse distress only $\left(\mathrm{Ps}_{0} \mathrm{Ph}_{0} \mathrm{D}_{1}\right)$

Psychological and physical abuse $\left(\mathrm{Ps}_{1} \mathrm{Ph}_{1} \mathrm{D}_{0}\right)$

Psychological abuse and substance abuse distress

$\left(\mathrm{Ps}_{1} \mathrm{Ph}_{0} \mathrm{D}_{1}\right)$

Physical abuse and substance abuse distress

$\left(\mathrm{Ps}_{0} \mathrm{Ph}_{1} \mathrm{D}_{1}\right)$

Psychological abuse, physical abuse and substance

abuse distress $\left(\mathrm{Ps}_{1} \mathrm{Ph}_{1} \mathrm{D}_{1}\right)$

\begin{tabular}{|c|c|c|c|}
\hline 1.00 & 1.00 & 1.00 & Ref \\
\hline $1.47(1.30-1.66)$ & $1.57(1.37-1.82)$ & $1.51(1.21-1.73)$ & $8.50(0.40-18.11)$ \\
\hline $1.32(1.08-1.60)$ & $1.45(1.14-1.76)$ & $1.38(1.10-1.68)$ & $12.49(-1.32-34.75)$ \\
\hline $1.11(0.97-1.27)$ & $1.11(0.93-1.27)$ & $1.07(0.93-1.21)$ & $36.11(-47.57-293.16)$ \\
\hline $1.58(1.38-1.80)$ & $1.78(1.50-2.03)$ & $1.54(1.32-1.77)$ & $24.41(15.90-36.83)$ \\
\hline $1.82(1.46-2.26)$ & $1.61(1.14-2.12)$ & $1.44(0.98-1.89)$ & 24.14(2.88-91.34) \\
\hline $1.33(0.86-2.04)$ & $1.69(0.91-2.61)$ & $1.63(0.88-2.50)$ & $7.13(-24.50-74.68)$ \\
\hline
\end{tabular}

$1.85(1.53-2.24)$

2.12(1.66-2.55)

$1.96(1.54-2.37)$

$10.56(1.61-20.92)$

\section{WELL-BEING (SWLS) $\boldsymbol{n}=8965$}

No trauma $\left(\mathrm{Ps}_{0} \mathrm{Ph}_{0} \mathrm{D}_{0}\right)$

1.00

1.33(1.21-1.47)

Psychological abuse only $\left(\mathrm{Ps}_{1} \mathrm{Ph}_{0} \mathrm{D}_{0}\right)$

Physical abuse only $\left(\mathrm{Ps}_{0} \mathrm{Ph}_{1} \mathrm{D}_{0}\right)$

Substance abuse distress only $\left(\mathrm{Ps}_{0} \mathrm{Ph}_{0} \mathrm{D}_{1}\right)$

Psychological and physical abuse $\left(\mathrm{Ps}_{1} \mathrm{Ph}_{1} \mathrm{D}_{0}\right)$

Psychological abuse and substance abuse distress

$\left(\mathrm{Ps}_{1} \mathrm{Ph}_{0} \mathrm{D}_{1}\right)$

Physical abuse and substance abuse distress

$\left(\mathrm{Ps}_{0} \mathrm{Ph}_{1} \mathrm{D}_{1}\right)$

Psychological abuse, physical abuse and substance abuse distress $\left(\mathrm{Ps}_{1} \mathrm{Ph}_{1} \mathrm{D}_{1}\right)$
1.24(1.06-1.45)

1.28(1.17-1.41)

1.57(1.43-1.73)

1.79(1.54-2.08)

0.93(0.60-1.43)

1.60(1.37-1.87)
1.00

1.29(1.15-1.43)

1.16(0.97-1.37)

1.24(1.11-1.37)

1.48(1.32-1.65)

1.62(1.31-1.92)

$0.87(0.47-1.34)$

1.46(1.21-1.75)
1.00

1.25(1.13-1.39)

1.12(0.93-1.32)

1.19(1.07-1.31)

1.31(1.19-1.46)

1.46(1.17-1.73)

$0.84(0.47-1.24)$

1.37(1.15-1.61)
Ref

13.55 (2.32-30.25)

25.02(-13.72-217.20)

17.60(6.33-34.57)

31.24(20.08-45.73)

22.36(5.64-43.85)

The binary outcomes of mental health, health, and well-being were used for mediation analysis.

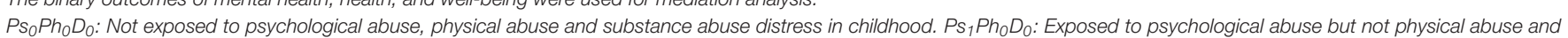

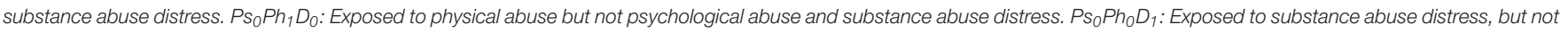

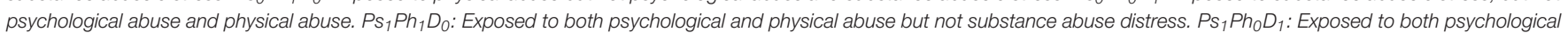

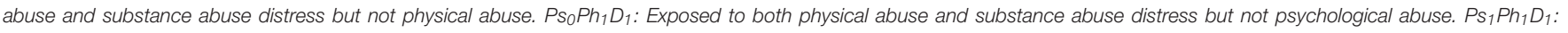
Exposed to psychological abuse, physical abuse, and substance abuse distress.

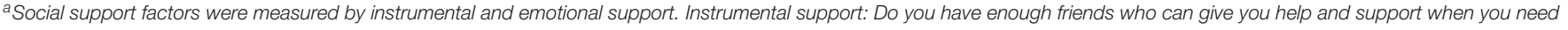
it? (yes, no); Emotional support: Do you have enough friends you can talk confidentially with? (yes, no).

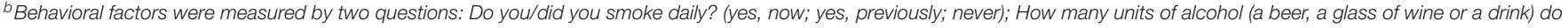
you usually drink when you drink alcohol? (1-4, 5-6, 7-9, 10 or more).

${ }^{c}$ Confounding variables were age, gender, father's education, mother's education and childhood financial conditions.

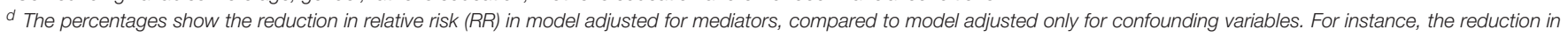
the RR for mental health for the $P s_{1} P h_{0} D_{0}$ group when including mediators to the first model, is $[(2.19-1.92) /(2.19-1.00)]$ * $100=22.88 \%$.

All significant associations ( $p<0.05)$ are in bold.

SCL-10: Mental health status was measured by the Hopkins Symptoms Check List-10 (SCL-10).

EQ-5D: Health was assessed by the EQ-5D generic measure of health-related quality of life.

SWLS: Well-being was measured by the satisfaction with life scale (SWLS). 
TABLE 12 | Effect of childhood traumatic experiences on mental health (SCL-10), health (EQ-5D), and subjective well-being (SWLS) in imputed dataset with multiple imputation ( $N=12,981)$.

\begin{tabular}{|c|c|c|c|c|}
\hline & Crude effects & Total effects & Direct effects & Indirect effects \\
\hline & Unadjusted & $\begin{array}{l}\text { Adjusted for } \\
\text { confounding variables }^{c}\end{array}$ & $\begin{array}{l}\text { Adjusted for confounding } \\
\text { variables }^{c} \text { and mediators }\end{array}$ & Proportion mediated $^{ \pm}$ \\
\hline & RR $(95 \% \mathrm{Cl})$ & RR $(95 \% \mathrm{Cl})$ & RR $(95 \% \mathrm{Cl})$ & \%attentuation $(95 \% \mathrm{Cl})$ \\
\hline \multicolumn{5}{|l|}{ MENTAL HEALTH (SCL-10) } \\
\hline No trauma $\left(\mathrm{Ps}_{0} \mathrm{Ph}_{0} \mathrm{D}_{0}\right)$ & 1.00 (ref) & 1.00 (ref) & 1.00 (ref) & Ref \\
\hline Psychological abuse only $\left(\mathrm{Ps}_{1} \mathrm{Ph}_{0} \mathrm{D}_{0}\right)$ & $2.04(1.66-2.51)$ & $1.94(1.57-2.17)$ & $1.62(1.47-1.90)$ & $25.63(17.42-39.59)$ \\
\hline Physical abuse only $\left(\mathrm{Ps}_{0} \mathrm{Ph}_{1} \mathrm{D}_{0}\right)$ & $1.06(0.69-1.64)$ & $1.12(0.68-1.65)$ & $1.01(0.59-1.45)$ & $90.96(-36.23-155.56)$ \\
\hline Substance abuse distress only $\left(\mathrm{Ps}_{0} \mathrm{Ph}_{0} \mathrm{D}_{1}\right)$ & $1.38(1.09-1-73)$ & $1.22(1.07-1.38)$ & $1.11(0.92-1.24)$ & $46.37(17.15-2343-.24)$ \\
\hline Psychological and physical abuse $\left(\mathrm{Ps}_{1} \mathrm{Ph}_{1} \mathrm{D}_{0}\right)$ & $2.41(1.95-2.98)$ & $2.30(1.96-2.63)$ & $1.73(1.55-2.03)$ & $34.44(26.60-37.47)$ \\
\hline $\begin{array}{l}\text { Psychological abuse and substance abuse } \\
\text { distress }\left(\mathrm{Ps}_{1} \mathrm{Ph}_{0} \mathrm{D}_{1}\right)\end{array}$ & $2.93(2.06-4.16)$ & $2.25(1.92-2.94)$ & $1.80(1.55-2.28)$ & $27.49(19.17-36.55)$ \\
\hline $\begin{array}{l}\text { Physical abuse and substance abuse distress } \\
\left(\mathrm{Ps}_{0} \mathrm{Ph}_{1} \mathrm{D}_{1}\right)\end{array}$ & $1.41(0.61-3.22)$ & $1.32(0.48-1.74)$ & $1.28(0.52-1.86)$ & $10.83(-40.78-86.25)$ \\
\hline $\begin{array}{l}\text { Psychological abuse, physical abuse and } \\
\text { substance abuse distress }\left(\mathrm{Ps}_{1} \mathrm{Ph}_{1} \mathrm{D}_{1}\right)\end{array}$ & $3.32(2.49-4.44)$ & $2.75(2.19-3.10)$ & 2.36 (1.89-2.82) & 15.04 (8.94-27.16) \\
\hline \multicolumn{5}{|l|}{ HEALTH (EQ-5D) } \\
\hline No trauma $\left(\mathrm{Ps}_{0} \mathrm{Ph}_{0} \mathrm{D}_{0}\right)$ & 1.00 (ref) & 1.00 (ref) & 1.00 (ref) & Ref \\
\hline Psychological abuse only $\left(\mathrm{Ps}_{1} \mathrm{Ph}_{0} \mathrm{D}_{0}\right)$ & $1.40(1.25-1.58)$ & $1.51(1.44-1.53)$ & $1.43(1.42-1.43)$ & $12.83(9.10-19.37)$ \\
\hline Physical abuse only $\left(\mathrm{Ps}_{0} \mathrm{Ph}_{1} \mathrm{D}_{0}\right)$ & $1.30(1.08-1.56)$ & $1.42(1.33-1.60)$ & $1.34(1.21-1.42)$ & $16.69(13.35-33.10)$ \\
\hline Substance abuse distress only $\left(\mathrm{Ps}_{0} \mathrm{Ph}_{0} \mathrm{D}_{1}\right)$ & $1.06(0.93-1.21)$ & $1.08(0.95-1.14)$ & 1.04 (0.93-1.10) & $43.65(-62.06-78.78)$ \\
\hline Psychological and physical abuse $\left(\mathrm{Ps}_{1} \mathrm{Ph}_{1} \mathrm{D}_{0}\right)$ & $1.50(1.32-1.71)$ & $1.63(1.47-1.79)$ & $1.45(1.33-1.64)$ & $24.27(18.59-31.55)$ \\
\hline $\begin{array}{l}\text { Psychological abuse and substance abuse } \\
\text { distress }\left(\mathrm{Ps}_{1} \mathrm{Ph}_{0} \mathrm{D}_{1}\right)\end{array}$ & $1.74(1.41-2.16)$ & $1.80(1.48-2.18)$ & $1.65(1.37-1.93)$ & $14.06(5.99-26.57)$ \\
\hline $\begin{array}{l}\text { Physical abuse and substance abuse distress } \\
\left(\mathrm{Ps}_{0} \mathrm{Ph}_{1} \mathrm{D}_{1}\right)\end{array}$ & $1.23(0.80-1.90)$ & $1.41(1.12-1.86)$ & $1.36(1.10-1.82)$ & $11.20(-5.80-41.01)$ \\
\hline $\begin{array}{l}\text { Psychological abuse, physical abuse and } \\
\text { substance abuse distress }\left(\mathrm{Ps}_{1} \mathrm{Ph}_{1} \mathrm{D}_{1}\right)\end{array}$ & $1.77(1.46-2.13)$ & 1.89 (1.47-1.99) & $1.76(1.43-1.86)$ & $11.53(4.06-19.01)$ \\
\hline \multicolumn{5}{|l|}{ WELL-BEING (SWLS) } \\
\hline No trauma $\left(\mathrm{Ps}_{0} \mathrm{Ph}_{0} \mathrm{D}_{0}\right)$ & 1.00 (ref) & 1.00 (ref) & 1.00 (ref) & Ref \\
\hline Psychological abuse only $\left(\mathrm{Ps}_{1} \mathrm{Ph}_{0} \mathrm{D}_{0}\right)$ & $1.34(1.22-1.47)$ & 1.27 (1.20-1.35) & $1.21(1.13-1.27)$ & $20.24(15.92-30.55)$ \\
\hline Physical abuse only $\left(\mathrm{Ps}_{0} \mathrm{Ph}_{1} \mathrm{D}_{0}\right)$ & $1.14(0.98-1.32)$ & 1.18 (1.12-1.28) & $1.13(1.05-1.21)$ & 29.34 (9.62-53.57) \\
\hline Substance abuse distress only $\left(\mathrm{Ps}_{0} \mathrm{Ph}_{0} \mathrm{D}_{1}\right)$ & $1.20(1.09-1.32)$ & $1.20(1.13-1.26)$ & $1.16(1.13-1.22)$ & 18.09 (10.65-27.64) \\
\hline Psychological and physical abuse $\left(\mathrm{Ps}_{1} \mathrm{Ph}_{1} \mathrm{D}_{0}\right)$ & $1.48(1.34-1.64)$ & $1.46(1.37-1.51)$ & $1.30(1.25-1.37)$ & $29.32(28.14-33.05)$ \\
\hline $\begin{array}{l}\text { Psychological abuse and substance abuse } \\
\text { distress }\left(\mathrm{Ps}_{1} \mathrm{Ph}_{0} \mathrm{D}_{1}\right)\end{array}$ & $1.72(1.47-2.01)$ & $1.62(1.42-2.00)$ & 1.49 (1.29-1.77) & 17.18 (8.19-27.91) \\
\hline Physical abuse and substance abuse distress & $0.87(0.51-1.48)$ & $0.91(0.72-1.19)$ & $0.89(0.67-1.14)$ & - \\
\hline
\end{tabular}

$\left(\mathrm{Ps}_{0} \mathrm{Ph}_{1} \mathrm{D}_{1}\right)$

Psychological abuse, physical abuse and

$1.44(1.21-1.71)$

$1.42(1.29-1.52)$

$1.33(1.21-1.44)$

$18.18(11.33-30.10)$

The binary outcomes of mental health, health, and well-being were used for mediation analysis.

$P s_{0} P h_{0} D_{0}$ : Not exposed to psychological abuse, physical abuse and substance abuse distress in childhood. $P_{s_{1}} P h_{0} D_{0}$ : Exposed to psychological abuse but not physical abuse and

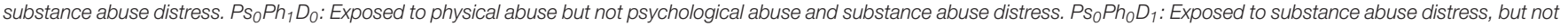

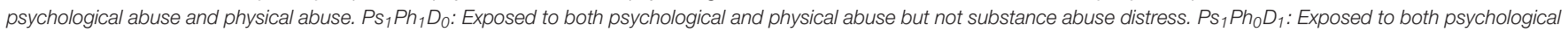
abuse and substance abuse distress but not physical abuse. $P S_{0} P h_{1} D_{1}$ : Exposed to both physical abuse and substance abuse distress but not psychological abuse. $P s_{1} P h_{1} D_{1}$ : Exposed to psychological abuse, physical abuse, and substance abuse distress.

a Social support factors were measured by instrumental and emotional support. Instrumental support: Do you have enough friends who can give you help and support when you need it? (yes, no); Emotional support: Do you have enough friends you can talk confidentially with? (yes, no).

${ }^{b}$ Behavioral factors were measured by two questions: Do you/did you smoke daily? (yes, now; yes, previously; never); How many units of alcohol (a beer, a glass of wine or a drink) do you usually drink when you drink alcohol? (1-4, 5-6, 7-9, 10 or more).

${ }^{\circ}$ Confounding variables were age, gender, father's education, mother's education and childhood financial conditions.

${ }^{ \pm}$The percentages show the reduction in relative risk (RR) in model adjusted for mediators, compared to model adjusted only for confounding variables. For instance, the reduction in the RR for mental health for the $P S_{1} P h_{0} D_{0}$ group when including mediators to the first model, is $[(1.94-1.62) /(1.94-1.00)]^{*} 100=25.63 \%$.

SCL-10: Mental health status was measured by the Hopkins Symptoms Check List-10 (SCL-10).

$E Q-5 D$ : Health was assessed by the EQ-5D generic measure of health-related quality of life.

SWLS: Well-being was measured by the satisfaction with life scale (SWLS).

All significant associations $(p<0.01)$ are in bold. 
each other) (Table 6). Compared to males, females had lower mental health, health, and well-being ( $p<0.01)$ (Table 6). Increased age was associated with lower health $(\beta=0.001$, 95\% CI: $0.001-0.001, p<0.001)$, but higher well-being $(\beta=$ $-0.001, p<0.01$ ) (Table 6). Lower mother's education was associated with lower health and well-being $(p<0.001)$; however, higher father's education was associated with lower well-being ( $\beta=0.005$, 95\% CI: 0.001-0.009) (Table 6). Having lower financial conditions in childhood was associated with lower mental health, health, and well-being in adulthood $(p<0.001)$ (Table 6). Having no instrumental support or emotional support was associated with lower mental health, health, and well-being $(p<0.001)$. Similarly, higher alcohol use and smoking was associated with lower mental health, health, and well-being in adulthood ( $p<0.01$ ) (Table 6).

Exposure to psychological abuse $\left(\mathrm{Ps}_{1} \mathrm{Ph}_{0} \mathrm{D}_{0}\right)$, psychological and physical abuse $\left(\mathrm{Ps}_{1} \mathrm{Ph}_{1} \mathrm{D}_{0}\right)$, psychological abuse and substance abuse distress $\left(\mathrm{Ps}_{1} \mathrm{Ph}_{0} \mathrm{D}_{1}\right)$, and exposure to all three CTEs $\left(\mathrm{Ps}_{1} \mathrm{Ph}_{1} \mathrm{D}_{1}\right)$ was significantly associated with lower mental health, health, and well-being (Table 6). However, exposure to physical abuse $\left(\mathrm{Ps}_{0} \mathrm{Ph}_{1} \mathrm{D}_{0}\right)$, and substance abuse distress $\left(\mathrm{Ps}_{0} \mathrm{Ph}_{0} \mathrm{D}_{1}\right)$ was significantly associated with lower mental health and well-being, but not lower health $(p>0.1)$ (Table 6).

\section{Associations between Childhood Traumatic Experiences, and Social Support and Behavioral Factors}

All mediators were significantly associated with CTEs (Table 7). The crude associations were mostly in the predicted direction, i.e., respondents with any CTE tend to be current or former smokers, were likely to have no friends to get support from and talk to, and drank five or more units of alcohol whenever they drank (Table 7). The crude associations indicate that for some combinations of CTEs, respondents were more likely to have friends to talk to, and be never smokers (Table 7). However, when the models were adjusted for all covariates, the direction of the association changed to what was expected, i.e., exposure to CTEs were associated with disadvantageous mediator values (data not shown). The test for linear trend $(p<0.01)$ showed that CTEs were associated with higher alcohol use (Table 7 ). In addition, the crude association between CTEs and the selected mediators was assessed with correspondence analysis (Greenacre, 2007, 2010). See Figure S3 in Online Supplementary Material.

\section{Association between Childhood Traumatic Experiences and Mental Health, Health, and Well-Being with Quantile Regression Model}

Table 8 presents the association between different combinations of CTEs and mental health, health, and well-being. The test of linear trend $(p<0.001)$ shows that trauma frequency was associated with lower mental health, health, and well-being. However, the estimates showed that the association may not be linear. Compared to those with no CTEs, exposure to any one or two types of CTEs led to similar association for both mental health $(\beta=0.03, p<0.001)$, and health $(\beta=0.03, p<0.001)$.
Similarly, the association with well-being $(\beta=0.06, p<0.05)$ remained the same for being exposed to any one, any two, or all three CTEs (Table 8).

Compared to those exposed to substance abuse distress, exposure to psychological abuse was associated with lower mental health $(\beta=0.03$, 95\% CI: 0.02-0.05, $p<0.001)$. Similarly, compared to those exposed to substance abuse distress, exposure to both psychological abuse and physical abuse was associated with lower mental health ( $\beta=0.04,95 \%$ CI: $0.01-0.06$, $p<0.01)$.

Compared to those exposed to physical abuse, exposure to both psychological abuse and substance abuse distress was associated with lower mental health $(\beta=0.03, p<0.1)$, and wellbeing $(\beta=0.06, p<0.1)$. Similarly, compared to those exposed to both physical abuse and substance abuse distress, exposure to psychological abuse was associated with lower well-being ( $\beta=$ 0.06, $p<0.1$ ). Moreover, compared to those exposed to both physical abuse, and substance abuse distress, exposure to all the three CTEs was associated with lower mental health $(\beta=0.08$, 95\% CI: 0.01-0.14), and health $(\beta=0.04, p<0.1)$ (Table 8).

\section{Associations between Social Support, Behavioral Factors, and Mental Health, Health, and Well-Being}

Table 9 shows the distribution of mediators by mental health, health, and well-being. The crude distributions between mediators and health and well-being showed that all mediators were significantly associated with mental health, health, and well-being in adulthood (Table 9). The crude associations were in the predicted direction, i.e., those who were current or former smokers, had no friends to get support from and talk to, and drank five or more units of alcohol whenever they drank, tend to be unhealthy and have a low level of well-being (Table 9). In addition, the crude association between mediators, and mental health, health, and well-being (using alternative cut-offs for health and well-being) was assessed with correspondence analysis (Greenacre, 2007, 2010). See Figure S4 in Online Supplementary Material.

Table 10 shows the association between mediators and mental health, health and well-being. Both the complete-case analysis (excluding missing), and the imputed dataset analysis are presented. Analyses conducted on the imputed dataset showed that the estimates for mental health, health, and well-being were mostly similar to those in the complete-case dataset. Having no instrumental support, no emotional support, higher alcohol use, and being a daily smoker was associated with an increased risk of being mentally unhealthy, unhealthy, and a low level of well-being (Table 10).

Among the two indicators of social support, having no instrumental support led to a higher risk for being mentally unhealthy $(\mathrm{RR}=2.49$ for instrumental support $v s$. $\mathrm{RR}=1.87$ for emotional support) and unhealthy ( $\mathrm{RR}=1.52$ for instrumental support $v s . \mathrm{RR}=1.29$ for emotional support), while having no instrumental support or emotional support led to a similar increased risk for having a low level of well-being $(\mathrm{RR}=1.40)$ (Table 10). The test for linear trend $(p<0.001)$ showed that 
increased alcohol use was associated with being unhealthy and having a low level of well-being (Table 10).

\section{Total Effects: The Association between Childhood Traumatic Experiences and Mental Health, Health, and Well-Being in Adulthood}

Statistically significant multiplicative interactions $(p<0.05)$ were observed between the three CTEs in childhood (data not shown). Figure 1 shows the interaction between physical abuse and substance abuse distress on subjective well-being scale (from unadjusted OLS model). The influence of physical abuse on wellbeing changed depending on exposure to substance abuse distress (Figure 1).

Those exposed to CTEs tend to be unhealthy and have a low level of well-being (Tables 6-8). All potential confounding variables and mediators were assessed for multiplicative interactions with the CTE combinations. However, there was no evidence of interaction beyond what would be expected by chance alone (data not shown) for any of our outcomes, and the cross-product terms were not included in the final models.

Tables 11, 12 presents the estimates for the risk of being mentally unhealthy, unhealthy, and having a low level of wellbeing with exposure to CTEs (reference: not exposed to any of the three CTEs). Four estimates are presented: crude (unadjusted), adjusted for confounding variables (total effects), adjusted for confounding variables and mediators (direct effects) and indirect effects in the form of proportion mediated (\% attenuation). The unadjusted (crude) associations show that being exposed to most combinations of CTEs significantly $(p<0.05)$ increased the risk of being mentally unhealthy, unhealthy and having a low level of well-being (Table 11).

Table 12 presents the analyses on imputed dataset with MI. After controlling for confounding variables, there was a significant, increased risk of being unhealthy and of having a low level of well-being for most combinations of CTEs (Table 12).

\section{Direct Effects: The Association between Childhood Traumatic Experiences and Mental Health, Health, and Well-Being in Adulthood, Adjusted for Social Support and Behavioral Factors}

Tables 11, 12 presents the direct effects (adjusted for confounding variables and mediators). The direct effects show that exposure to psychological abuse only $\left(\mathrm{Ps}_{1} \mathrm{Ph}_{0} \mathrm{D}_{0}\right)$, exposure to both psychological and physical abuse $\left(\mathrm{Ps}_{1} \mathrm{Ph}_{1} \mathrm{D}_{0}\right)$, and exposure to all the three CTEs $\left(\mathrm{Ps}_{1} \mathrm{Ph}_{1} \mathrm{D}_{1}\right)$ in childhood significantly $(p<0.05)$ increased the risk of being mentally unhealthy (Table 11). However, for health and well-being, exposure to most combinations of CTEs significantly $(p<0.05)$ increased the risk of being unhealthy, and having a low level of well-being (Table 11).

The results from the imputed dataset showed that exposure to most combinations of CTEs significantly $(p<0.01)$ increased the risk of being unhealthy, and having a low level of well-being (Table 12). Generally, the risk for being mentally unhealthy was greater than being unhealthy (Table 12). Similarly, the risk for being unhealthy was greater than having a low level of well-being (Table 12). Exposure to psychologically abuse was associated with a higher risk for being mentally unhealthy, unhealthy, and having a low level of well-being. Those exposed to all three types of CTEs $\left(\mathrm{Ps}_{1} \mathrm{Ph}_{1} \mathrm{D}_{1}\right)$ had a more than two-fold increased risk of being mentally unhealthy $\left(\mathrm{RR}_{\text {Direct Effect }}=2.36,95 \%\right.$ CI: 1.89 $2.82)$, a $76 \%$ increased risk of being unhealthy $\left(\mathrm{RR}_{\text {Direct Effect }}=\right.$ $1.76,95 \% \mathrm{CI}: 1.43-1.86)$, and a $33 \%$.increased risk of having a low level of well-being $\left(\mathrm{RR}_{\text {Direct Effect }}=1.33,95 \% \mathrm{CI}\right.$ : 1.21-1.44) (Table 12).

Analysis conducted on the imputed dataset (Table 12) show that the estimates for direct effects (and 95\% CIs) for health and well-being were nearly the same as those in the complete-case dataset presented in Table 11. However, the estimates for mental health had a slightly different magnitude. After controlling for confounding variables and mediators, the complete-case analyses might even suggest a protective effect of being exposed to substance abuse distress only $\left(\mathrm{RR}_{\text {Direct Effect }}=0.93,95 \%\right.$ CI: 0.68 1.29) (Table 11), while in the imputed dataset the $R R_{\text {Direct Effect }}$ estimate was 1.11 (95\% CI: 0.92-1.24) (Table 12), which is more plausible.

In most of the models, there was a statistically significant association between CTEs and mental health, health, and wellbeing after adjusting for mediators. Furthermore, some of the models that were not statistically significant $(p \geq 0.05)$ in the complete-case dataset (Table 11) were statistically significant $(p<0.01)$ in the imputed dataset (Table 12), and were in the same direction.

\section{Indirect Effects: The Proportion of Mediated Effect (\% Attenuation) by Social Support and Behavioral Factors}

Tables 11, 12 presents the indirect effects (proportion mediated). The role of mediators was explored by including them in the model adjusted for confounding variables (Tables 11, 12). After adjusting for mediators, the estimates for both psychological abuse and physical abuse $\left(\mathrm{Ps}_{1} \mathrm{Ph}_{1} \mathrm{D}_{0}\right)$ were attenuated by $24-41 \%$, while the estimates for both psychological abuse and substance abuse $\left(\mathrm{Ps}_{1} \mathrm{Ph}_{0} \mathrm{D}_{1}\right)$ were attenuated by $22-54 \%$ (Table 11).

Results from the imputed dataset (Table 12) showed that some of the indirect effects may be underestimated in the complete-case analyses (Table 11). After adjusting for mediators, the estimates for psychological abuse only $\left(\mathrm{Ps}_{1} \mathrm{Ph}_{0} \mathrm{D}_{0}\right)$ and health and well-being were attenuated by $12-25 \%$; while the associations with exposure to all the three CTEs were attenuated by 1118\% (Table 12). The indirect effects for health and well-being when using the alternative cut offs (See Tables S7, S8 in Online Supplementary Material) showed that they were very similar to the indirect effects presented in Tables 11, 12. This shows that the indirect effects are robust to how the cut offs are made for health and well-being outcomes.

In summary, the results showed a direct effect of psychological abuse, physical abuse, and substance abuse distress in childhood 
on mental health, health, and well-being in adulthood, and that some of this affect was mediated through social support and behavioral factors in adulthood.

\section{DISCUSSION AND CONCLUSION}

Among all the variables considered, CSES explained most variation in instrumental support and smoking, while sociodemographic variables explained most variation in emotional support and alcohol use. Instrumental support explained most of the variation in mental health, while gender explained most of the variation in health, and emotional support explained most of the variation in well-being. CTEs were relatively more important to mental health than CSES. However, CSES were relatively more important to health and well-being than CTEs. Social support factors were relatively more important to mental health, health, and well-being, as compared to behavioral factors. Moreover, when mental health was included, it explained most variation in both health, and well-being.

Exposure to psychological abuse, both psychological and physical abuse, and both psychological abuse and substance abuse distress was associated with lower mental health, health, and well-being. Similarly, exposure to all the three CTEs was also associated with lower mental health, health, and wellbeing. Exposure to CTEs was associated with having no social support, being a smoker, and a higher alcohol consumption. Consequently, social support and behavioral factors were associated with lower mental health, health, and well-being.

Consistent with previous studies (Dias et al., 2014), significant multiplicative interactions were observed between the three CTEs. We observed a direct effect of CTEs on adult health and well-being after controlling for selected social support and behavioral factors, but some of this effect was mediated by these factors. These findings support the "chain of risk" model proposed in life course epidemiology. A naïve interpretation would be that a substantial effect of CTEs on adult health and well-being can be reduced by programs/interventions aimed at improving conditions for a social life, and reducing cigarette and alcohol consumption. This paper shows that structural conditions such as CTEs act partly through agency-driven social support and behavioral patterns in adulthood to determine health and well-being. Thus, the standard approach for targeting these individuals to change their behavior will fail as long as these structural conditions remain, as these conditions will pave the way for new mediators to emerge. Assuming that people have a choice to quit smoking, drink less alcohol, and keep an active social life for better health and well-being may not be correct. We have only looked at three types of CTEs, and there can be many structural conditions (Korbin et al., 1998; Coulton et al., 1999) deeply rooted in any society which prevent individuals from making choices freely.

Other models proposed in the life course epidemiology theory include the "sensitive period model," and the "critical period model" (Ben-Shlomo and Kuh, 2002). The sensitive period model suggests that exposure during a sensitive period may have stronger effects on health, whereas the critical period model suggests that the effect of exposure is only influential if it occurs at a certain "critical" period of life. Our findings are not related to either of these models, since we did not assess the relative importance of similar traumatic experiences from different periods of life.

Contrary to the findings by Lamu and Olsen (2016) health seemed to be more important to subjective well-being, as compared to social support factors. The results were consistent when we used the EQ visual analog scale of health (EQ VAS), and preference-based utility scores of EQ-5D (data not shown). A notable feature of the Shapley decomposition is that it is a function of the group of predictors considered (Hoyos and Narayan, 2011). This is a result of the fact that the Shapley decomposition is sensitive only to variation between predictors, which would naturally vary with the number of predictors considered. Therefore, the relative contribution of the different life circumstances presented here may vary from that presented in other studies. Furthermore, consistent with previous findings (Mäkinen et al., 2006; Sheikh et al., 2014), mother's/father's education is relatively less important for health and well-being, as compared to the subjective assessment of childhood financial conditions. No previous study was found that assessed the relative contribution of CSES, CTEs, and behavioral factors for mental health, health, and well-being.

The results of this study show that the association between CTEs and health and well-being in adulthood varies substantially depending on the type of traumatic experience. This clearly indicates that the unique effect of each type of CTEs is lost by using the sum score of trauma frequency. In line with previous studies, we showed that CTEs are associated with mental health, health, and well-being in adulthood independent of risk factors in adulthood. Consistent with previous studies (Ney, 1987; Martin et al., 2006; Norman et al., 2012; Dias et al., 2014; Spinazzola et al., 2014; Auslander et al., 2015; Friborg et al., 2015), psychological abuse in childhood was associated with a higher risk for being mentally unhealthy and unhealthy, as compared to physical abuse.

Most previous studies, though not all (Widom et al., 2007; Fergusson et al., 2008; Agorastos et al., 2014), have shown that CTEs are associated with social support and behavioral factors in adulthood. The results of this study support this. Higher alcohol use among victims of CTEs may reflect the need to reduce feelings of isolation and loneliness (Widom et al., 1995; Widom and Hiller-Sturmhofel, 2001). In this way, alcohol use may act as a mediator in the association between social support factors, and health and well-being in adulthood. Future studies should address this question.

In this dataset, we observed that other structural conditions, such as gender and socioeconomic adversities in childhood are important to health and well-being in adulthood. However, they do not play a moderating role in the association between CTE combinations and adult health and well-being. Some studies have suggested that socioeconomic factors and CTEs may interact to increase one's vulnerability to traumatic experiences in childhood (Schilling and Christian, 2014), but we found no statistically significant multiplicative interaction between CTE combinations and any of the confounding variables (data not 
shown). Previous studies have reported statistically significant multiplicative interactions between adversities in childhood and adversities in adulthood in predicting certain negative health outcomes (Kessler and Magee, 1994; Mock and Arai, 2011; Aas et al., 2014; Sheikh et al., 2014), whereas we did not find convincing evidence in this study (data not shown). Some evidence (Horwitz et al., 2001; Chartier et al., 2010; Axinn et al., 2013; De Bellis and Zisk, 2014; Horan and Widom, 2014), though not all (Greenfield and Marks, 2009, 2010; Springer, 2009; Greenfield et al., 2011), suggests that gender may be a moderator of CTEs, or of behavioral factors (Widom and White, 1997). As we found no such evidence in our sample, estimates are provided for men and women combined. Similarly, no statistically significant multiplicative interaction with age was observed in our sample (data not shown).

Most previous studies (McLeod, 1991; Harper et al., 2002; Luo and Waite, 2005; Fors et al., 2009; Gibb et al., 2012; Morgan et al., 2014; Monnat and Chandler, 2015; Pavela and Latham, 2015), though not all (Danese et al., 2009; Park et al., 2013; Sheikh et al., 2014), have suggested that adult socioeconomic status (ASES) mediates the effect of childhood adversities on indicators of health in adulthood. The crude associations between CTE combinations and ASES (measured using the variables: education, having full-time occupation, income, and subjective social status) did not show a clear pattern (data not shown). Similarly, the association between CTEs, and subjective social status in adulthood was not statistically significant (data not shown). These are key assumptions that must be satisfied before assessing mediation (Judd and Kenny, 1981; Baron and Kenny, 1986). Consequently, including ASES in the regression models (adjusted for confounding variables, and social support and behavioral factors) barely attenuated the estimates of CTEs (Sheikh, 2015), and ASES was thus not included in the final analyses. If the models are only adjusted for ASES (and not social support and behavioral factors), the attenuation in estimates may be due to the association between ASES and social support and behavioral factors. In this case, ASES may serve as a surrogate mediator, and the estimates will be attenuated depending on the strength of the correlation between ASES and social support and behavioral factors. It is plausible that in the absence (or mismeasurement) of social support and behavioral factors in the models, previous studies concluded that ASES mediates the association between childhood adversity and health in adulthood. One possible reason for ASES not being a mediator in our study sample may be the Norwegian welfare state, and the presence of free education at all levels. This means that even respondents with disadvantaged backgrounds may still obtain the necessary education to build a career. Moreover, respondents with severe traumatic experiences and difficulty in keeping a stable job or in landing a high-income job due to behavioral or psychological problems may still not be poor in absolute terms, as the welfare benefits provide for the basic amenities in life.

It is plausible that different mechanisms apply to different respondents in the sample. For instance, there may be a subset of the sample, for which the mediators do not operate by the hypothesized mechanism. For example, previous research has shown that children growing up in a violent environment have high levels of life satisfaction and optimism (Veronese et al., 2012b). Other evidence suggests that some children are not affected by psychological and social problems despite traumatic experiences (Luthar et al., 2000). This "resilience" may be explained by genetic factors (Lykken and Tellegen, 1996; Frey, 2011), positive emotions (Veronese et al., 2012a,c), and contextual factors (Fergusson and Lynskey, 1997; Veronese et al., 2012b; Veronese and Castiglioni, 2015), that enable the children to develop a resilient identity. This may be detected by the significance and magnitude of product terms involving sociodemographic variables (where socio-demographic variables may serve as a proxy for genetic and contextual factors). However, since the empirical tests of multiplicative interactions involving multiple factors are notoriously underpowered (Marshall, 2007), the possibility of moderation cannot be ruled out. On the contrary, other evidence suggests that physical and psychological abuse in childhood has consequences on a molecular level (thus, cannot be manipulated by the subject), even when culturally or contextually acceptable (Hecker et al., 2016).

This study has some limitations. An important assumption when assessing mediation (indirect effects) is temporality (Nguyen et al., 2015). The mediators must precede the outcomes, and the exposure must precede the mediators. We acknowledge that the temporality between mediators and mental health, health, and well-being cannot be determined empirically in this study. There may be some reverse causation, as those who are unhealthy are likely to experience problems in interpersonal relations. Therefore, the present study cannot determine whether the factors in adulthood are the cause, or the consequence of poor health/low well-being.

The retrospective account of CTEs may be subject to recall bias (Cohen et al., 1997; Gilbert, 2006), deleterious effects on memory among those suffering from clinical states (such as anxiety and depression), and retrieval bias among those with clinical states (Brewin et al., 1993; Williams, 1994; Goldsmith et al., 2009; Saunders and Adams, 2014). It could be argued that unhealthy individuals maybe more likely to report or recall CTEs. However, a review of the evidence suggests that these biases should be fairly low (Brewin et al., 1993).

The cut-offs used in this manuscript are aimed to separate the "most unhealthy"/"lowest well-being" from the rest. We performed all analyses using the alternative cut-offs ("perfectly healthy/highest well-being" vs. the rest) and the results were consistent in the same direction (see Online Supplementary Material). We acknowledge that the measures of mental health, health, and well-being were dichotomized for mediation analysis, and thus lost much of their variation. All three dependent variables did not fulfill the normality assumptions for the OLS regression model that are needed for hypothesis testing. An alternative solution would have been to use quantile regression models, but so far no methodological approach for assessing mediation with quantile regression has been established in the literature. However, we assessed mediation with alternative cut-offs, and the results remained 
consistent in the same direction (see Online Supplementary Material).

It should be noted that the magnitude of RRs also reflects the way the cut-offs for the outcome variables are made. The cutoff for the SCL-10 was based on prior research (Strand et al., 2003; Kvamme et al., 2011). It is likely that the RRs would have been different in magnitude had we used a different cutoff. However, the direction of the effects proved to remain the same for other cut-offs that we tested (see Online Supplementary Material).

Assessing mediation with the measure of proportion mediated (Susser, 1973; Szklo and Nieto, 2000; Kaufman et al., 2004) is not without limitations (MacKinnon, 2008). The CIs for this measure are often wide, and have no limit. This is particularly apparent when the effect size (total effect) is small or when the direct effect is very close to null $\left(\mathrm{RR}_{\text {Direct Effect }} \approx 1.00\right)$. The confidence interval of proportion mediated (\% attenuation) may include many values far greater than $100 \%$, simply because many random samples from the study sample, may estimate the total effect or the direct effects less than 1.00. Similarly, the proportion mediated measure does not provide a valid interpretation when there is inconsistent mediation, such that the direct and indirect effects have opposite signs; potentially arising from selection bias by list-wise deletion. In the case of mental health, estimates for $\mathrm{Ps}_{0} \mathrm{Ph}_{1} \mathrm{D}_{1}$ demonstrate this problem, as the estimate for direct effect increased (as compared to total effects) after including the mediators in the models (Table 11). This was not the case when multiple imputed dataset was used for analysis (Table 12). Still, for what it is worth; proportion mediated provides a simple explanation of the indirect effect in terms of percentages.

We acknowledge that the three measures of mental health, health, and well-being used in this study were not commonly used in the previous psychology literature. We performed multiple statistical tests to address the research questions, and this may increase the probability of obtaining a type I error. Previous studies have shown that significance probability should not be adjusted (for instance, using $p<0.01$, instead of $p<$ 0.05 ) to reduce the chance of type I error, as doing so may increase the probability of type II error (Rothman, 1990; Feise, 2002).

We classified the experience of having a close family member using alcohol or drugs in such a way that it caused worry as "substance abuse distress." We acknowledge that this classification may be misleading since the variable probably represents the worry of witnessing problematic drinking or drug use by a family member. It cannot be established empirically from the data whether the worry was enough to be established as distress, as this is a theoretical question. The results from the imputed dataset (Tables 6, 12) showed that substance abuse distress was significantly associated with mental health and wellbeing, but not health. This implies that the effect of this worry, classified as substance abuse distress, is long-term, at least for mental health and subjective well-being. Whether this specific type of distress merits classification as a CTE is beyond the scope of this paper. The strengths of this study lie in its large representative population sample, its estimates of different types of CTEs, and the use of three multi-item instruments for mental health, health, and well-being.

This study contributes to the growing literature (Dube et al., 2001; Baker et al., 2009; Fors et al., 2009; Mock and Arai, 2011; Landes et al., 2014; Raposo et al., 2014; Sheikh et al., 2014; van Nierop et al., 2014; Gilman et al., 2015; May-Ling et al., 2015; Pavela and Latham, 2015) on the assessment of lifetime pathways from childhood adversity to mental health, health, and well-being in adulthood. Using Shapley decomposition for dissimilarity index and $R^{2}$, we showed the relative contribution of socio-demographic factors, CSES, CTEs, social support and behavioral factors for mental health, health, and well-being. We used the "difference method" approach to assess mediation. The estimates were adjusted for potential confounding variables, and the multiplicative interaction between the types of CTEs was considered. Our findings suggest that childhood traumatic experiences increase the risk of being unhealthy and having a low level of well-being, and that some of this effect is mediated by social support and behavioral factors in adulthood.

\section{ETHICS STATEMENT}

The Tromsø Study has been approved by the Regional Committee for Medical and Health Research Ethics, the Data Inspectorate and the Norwegian Directorate of Health. Written informed consent was obtained from all individual participants included in the study.

\section{AUTHOR CONTRIBUTIONS}

This work was completed as part of MS's PhD. MS planned the study, performed statistical analyses, data interpretation, developed the theory and drafted the manuscript. BA and JO critically commented on the manuscript.

\section{FUNDING}

This work was funded by the University of Tromsø, Norway.

\section{ACKNOWLEDGMENTS}

We are thankful to Jonathan Bartlett for fruitful comments on multiple imputation, and Michael Greenacre and Raul Primicerio for fruitful comments on correspondence analysis.

\section{SUPPLEMENTARY MATERIAL}

The Supplementary Material for this article can be found online at: http://journal.frontiersin.org/article/10.3389/fpsyg. 2016.00727 


\section{REFERENCES}

Aas, M., Etain, B., Bellivier, F., Henry, C., Lagerberg, T., Ringen, A., et al. (2014). Additive effects of childhood abuse and cannabis abuse on clinical expressions of bipolar disorders. Psychol. Med. 44, 1653-1662. doi: 10.1017/S0033291713002316

Agorastos, A., Pittman, J. O. E., Angkaw, A. C., Nievergelt, C. M., Hansen, C. J., Aversa, L. H., et al. (2014). The cumulative effect of different childhood trauma types on self-reported symptoms of adult male depression and PTSD, substance abuse and health-related quality of life in a large active-duty military cohort. J. Psychiatr. Res. 58, 46-54. doi: 10.1016/j.jpsychires.2014. 07.014

Alloy, L. B., Abramson, L. Y., Walshaw, P. D., Keyser, J., and Gerstein, R. K. (2006). A cognitive vulnerability-stress perspective on bipolar spectrum disorders in a normative adolescent brain, cognitive, and emotional development context. Dev. Psychopathol. 18, 1055-1103. doi: 10.1017/S0954579406060524

American Psychiatric Association (2013). Diagnostic and Statistical Manual of Mental Disorders, 5th Edn. Arlington, VA: American Psychiatric Publishing.

Armstrong, D. (2009). Origins of the problem of health-related behaviours: a genealogical study. Soc. Stud. Sci. 39, 909-926. doi: 10.1177/0306312709104258

Auslander, W., Tlapek, S. M., Threlfall, J., Edmond, T., and Dunn, J. (2015). Mental health pathways linking childhood maltreatment to interpersonal revictimization during adolescence for girls in the child welfare system. J. Int. Violence. doi: 10.1177/0886260515614561. [Epub ahead of print].

Axinn, W. G., Ghimire, D. J., Williams, N. E., and Scott, K. M. (2013). Gender, traumatic events, and mental health disorders in a rural asian setting. J. Health Soc. Behav. 54, 444-461. doi: 10.1177/0022146513501518

Baker, C., Norris, F., Jones, E., and Murphy, A. (2009). Childhood trauma and adulthood physical health in Mexico. J. Behav. Med. 32, 255-269. doi: 10.1007/s10865-009-9199-2

Baron, R. M., and Kenny, D. A. (1986). The moderator-mediator variable distinction in social psychological research: conceptual, strategic, and statistical considerations. J. Pers. Soc. Psychol. 51, 1173-1182. doi: 10.1037/00223514.51.6.1173

Barros, A., and Hirakata, V. (2003). Alternatives for logistic regression in crosssectional studies: an empirical comparison of models that directly estimate the prevalence ratio. BMC Med. Res. Methodol. 3:21. doi: 10.1186/1471-2288-3-21

Barros, R. P., Ferreira, F. H. G., Vega, J. R. M., and Chanduvi, J. S. (2009). Measuring Inequality of Opportunities in Latin America and the Caribbean. Washington, DC: The International Bank for Reconstruction and Development/The World Bank.

Barros, R. P., Vega, J. R. M., and Saavedra, J. (2010). Measuring progress toward basic opportunities for all. Brazil. Rev. Economet. 30, 335-367. Available online at: http://bibliotecadigital.fgv.br/ojs/index.php/bre/article/view/3687

Ben-Shlomo, Y., and Kuh, D. (2002). A life course approach to chronic disease epidemiology: conceptual models, empirical challenges and interdisciplinary perspectives. Int. J. Epidemiol. 31, 285-293. doi: 10.1093/ije/31.2.285

Brewin, C. R., Andrews, B., and Gotlib, I. H. (1993). Psychopathology and early experience: a reappraisal of retrospective reports. Psychol. Bull. 113, 82-98. doi: 10.1037/0033-2909.113.1.82

Briere, J. (2002). "Treating adult survivors of severe childhood abuse and neglect: further development of an integrative model," in The APSAC Handbook on Child Maltreatment, 2nd Edn., eds J. E. B. Myers, L. Berliner, J. Briere, C. T. Hendrix, T. Reid, and C. Jenny (Thousand Oaks, CA: Sage), 175-203.

Cancel, A., Comte, M., Truillet, R., Boukezzi, S., Rousseau, P. F., Zendjidjian, X. Y., et al. (2015). Childhood neglect predicts disorganization in schizophrenia through grey matter decrease in dorsolateral prefrontal cortex. Acta Psychiatrica Scand. 132, 244-256. doi: 10.1111/acps.12455

Carpenter, J., and Bithell, J. (2000). Bootstrap confidence intervals: when, which, what? A practical guide for medical statisticians. Stat. Med. 19, 1141-1164. doi: 10.1002/(SICI)1097-0258(20000515)19:9<1141::AID-SIM479>3.0.CO;2-F

Chartier, M. J., Walker, J. R., and Naimark, B. (2010). Separate and cumulative effects of adverse childhood experiences in predicting adult health and health care utilization. Child Abuse Neglect 34, 454-464. doi: 10.1016/j.chiabu.2009.09.020

Clogg, C. C., Petkova, E., and Shihadeh, E. S. (1992). Statistical methods for analyzing collapsibility in regression models. J. Educ. Behav. Stat. 17, 51-74. doi: $10.3102 / 10769986017001051$
Cohen, S., Kessler, R. C., and Gordon, L. U. (1997). Measuring Stress: A Guide for Health and Social Scientists. New York, NY: Oxford University Press.

Cole, P. M., and Putnam, F. W. (1992). Effect of incest on self and social functioning: a developmental psychopathology perspective. J. Consult. Clin. Psychol. 60, 174-184. doi: 10.1037/0022-006X.60.2.174

Coulton, C. J., Korbin, J. E., and Su, M. (1999). Neighborhoods and child maltreatment: a multi-level study. Child Abuse Neglect 23, 1019-1040. doi: 10.1016/S0145-2134(99)00076-9

Crossley, T. F., and Kennedy, S. (2002). The reliability of self-assessed health status. J. Health Econ. 21, 643-658. doi: 10.1016/S0167-6296(02)00007-3

Danese, A., Moffitt, T. E., Harrington, H., Milne, B. J., Polanczyk, G., Pariante, C. M., et al. (2009). Adverse childhood experiences and adult risk factors for age-related disease: depression, inflammation, and clustering of metabolic risk markers. Arch. Pediat. Adoles. Med. 163, 1135-1143. doi: 10.1001/archpediatrics.2009.214

Daruy-Filho, L., Brietzke, E., Lafer, B., and Grassi-Oliveira, R. (2011). Childhood maltreatment and clinical outcomes of bipolar disorder. Acta Psychiatr. Scand. 124, 427-434. doi: 10.1111/j.1600-0447.2011.01756.x

Davis, J. L., Petretic-Jackson, P. A., and Ting, L. (2001). Intimacy dysfunction and trauma symptomatology: long-term correlates of different types of child abuse. J. Trauma. Stress 14, 63-79. doi: 10.1023/A:1007835531614

De Bellis, M. D., and Zisk, A. (2014). The biological effects of childhood trauma. Child Adoles. Psychiat. Clin. 23, 185-222. doi: 10.1016/j.chc.2014.01.002

Dias, A., Sales, L., Hessen, D. J., and Kleber, R. J. (2014). Child maltreatment and psychological symptoms in a Portuguese adult community sample: the harmful effects of emotional abuse. Eur. Child Adoles. Psychiatry 24, 767-778. doi: 10.1007/s00787-014-0621-0

Diener, E., Emmons, R. A., Larsen, R. J., and Griffin, S. (1985). The satisfaction with life scale. J. Pers. Assess. 49, 71-75. doi: 10.1207/s15327752jpa4901_13

Dong, M., Dube, S. R., Felitti, V. J., Giles, W. H., and Anda, R. F. (2003). Adverse childhood experiences and self-reported liver disease: new insights into the causal pathway. Arch. Intern. Med. 163, 1949-1956. doi: 10.1001/archinte.163.16.1949

Dube, S. R., Anda, R. F., Felitti, V. J., Chapman, D. P., Williamson, D. F., and Giles, W. H. (2001). Childhood abuse, household dysfunction, and the risk of attempted suicide throughout the life span: findings from the adverse childhood experiences study. J. Am. Med. Asso. 286, 3089-3096. doi: 10.1001/jama.286.24.3089

Edwards, V. J., Holden, G. W., Felitti, V. J., and Anda, R. F. (2003). Relationship between multiple forms of childhood maltreatment and adult mental health in community respondents: results from the adverse childhood experiences study. Am. J. Psychiatry 160, 1453-1460. doi: 10.1176/appi.ajp.160. 8.1453

Fagundes, C. P., and Way, B. (2014). Early-life stress and adult inflammation. Curr. Dir. Psychol. Sci. 23, 277-283. doi: 10.1177/0963721414535603

Feise, R. J. (2002). Do multiple outcome measures require p-value adjustment? BMC Med. Res. Methodol. 2:8. doi: 10.1186/1471-2288-2-8

Felitti Md, F. V. J., Anda Md, M. S. R. F., Nordenberg Md, D., Williamson Ms, P. D. F., Spitz Ms, M. P. H. A. M., Edwards Ba, V., et al. (1998). Relationship of childhood abuse and household dysfunction to many of the leading causes of death in adults: the adverse childhood experiences (ace) study. Am. J. Prev. Med. 14, 245-258. doi: 10.1016/S0749-3797(98)00017-8

Fergusson, D. M., Boden, J. M., and Horwood, L. J. (2008). Exposure to childhood sexual and physical abuse and adjustment in early adulthood. Child Abuse Neglect 32, 607-619. doi: 10.1016/j.chiabu.2006.12.018

Fergusson, D. M., and Lynskey, M. T. (1997). Physical punishment/maltreatment during childhood and adjustment in young adulthood. Child Abuse Neglect 21, 617-630. doi: 10.1016/S0145-2134(97)00021-5

Fors, S., Lennartsson, C., and Lundberg, O. (2009). Childhood living conditions, socioeconomic position in adulthood, and cognition in later life: exploring the associations. J. Gerontol. Ser. B Psychol. Sci. Soc. Sci. 64B, 750-757. doi: 10.1093/geronb/gbp029

Frey, B. S. (2011). Peace, war, and happiness:Bruder Klaus as wellbeing facilitator. Int. J. Wellbeing 1, 226-234. doi: 10.5502/ijw.v1i2.5

Friborg, O., Emaus, N., Rosenvinge, J. H., Bilden, U., Olsen, J. A., and Pettersen, G. (2015). Violence affects physical and mental health differently: the general population based tromsø study. PLOS ONE 10:e0136588. doi: 10.1371/journal.pone. 0136588 
Gaudiano, B. A., and Zimmerman, M. (2010). The relationship between childhood trauma history and the psychotic subtype of major depression. Acta Psychiatr. Scand. 121, 462-470. doi: 10.1111/j.1600-0447.2009.01477.x

Gayer-Anderson, C., Fisher, H., Fearon, P., Hutchinson, G., Morgan, K., Dazzan, P., et al. (2015). Gender differences in the association between childhood physical and sexual abuse, social support and psychosis. Soc. Psychiatry Psychiatr. Epidemiol. 50, 1-12. doi: 10.1007/s00127-015-1058-6

Gibb, S. J., Fergusson, D. M., and Horwood, L. J. (2012). Childhood family income and life outcomes in adulthood: findings from a 30-year longitudinal study in New Zealand. Soc. Sci. Med. 74, 1979-1986. doi: 10.1016/j.socscimed.2012.02.028

Gilbert, D. (2006). Stumbling on Happiness. New York, NY: Alfred A. Knopf/Vintage.

Gilman, S. E., Ni, M. Y., Dunn, E. C., Breslau, J., McLaughlin, K. A., Smoller, J. W., et al. (2015). Contributions of the social environment to first-onset and recurrent mania. Mol. Psychiatry 20, 329-336. doi: 10.1038/mp.2014.36

Goldsmith, R. E., Freyd, J. J., and DePrince, A. P. (2009). To Add insight to injury: childhood abuse, abuse perceptions, and the emotional and physical health of young adults. J. Agg. Maltreat. Trauma 18, 350-366. doi: $10.1080 / 10926770902901527$

Greenacre, M. (2007). Correspondence Analysis in Practice, 2nd Edn. Boca Raton, FL: CRC Press.

Greenacre, M. (2010). Biplots in Practice. Bilbao: Fundación BBVA.

Greenfield, E., Lee, C., Friedman, E., and Springer, K. (2011). Childhood abuse as a risk factor for sleep problems in adulthood: evidence from a U.S. National Study. Ann. Behav. Med. 42, 245-256. doi: 10.1007/s12160-011-9285-x

Greenfield, E. A., and Marks, N. F. (2009). Profiles of physical and psychological violence in childhood as a risk factor for poorer adult health: evidence from the 1995-2005 national survey of midlife in the United States. J. Aging Health 21, 943-966. doi: 10.1177/0898264309343905

Greenfield, E. A., and Marks, N. F. (2010). Identifying experiences of physical and psychological violence in childhood that jeopardize mental health in adulthood. Child Abuse Neglect 34, 161-171. doi: 10.1016/j.chiabu.2009.08.012

Greenland, S. (1987). Interpretation and choice of effect measures in epidemiologic analyses. Am. J. Epidemiol. 125, 761-768.

Greenland, S., Robins, J. M., and Pearl, J. (1999). Confounding and collapsibility in causal inference. Stat. Sci. 14, 29-46. Available online at: http://www.jstor.org/ stable/2676645

Harper, S., Lynch, J., Hsu, W. L., Everson, S. A., Hillemeier, M. M., Raghunathan, T. E., et al. (2002). Life course socioeconomic conditions and adult psychosocial functioning. Int. J. Epidemiol. 31, 395-403. doi: 10.1093/ije/ 31.2.395

Have, T. R. T., Elliott, M. R., Joffe, M., Zanutto, E., and Datto, C. (2004). Causal models for randomized physician encouragement trials in treating primary care depression. J. Am. Stat. Assoc. 99, 16-25. doi: 10.1198/016214504000000034

Hecker, T., Radtke, K. M., Hermenau, K., Papassotiropoulos, A., and Elbert, T. (2016). Associations among child abuse, mental health, and epigenetic modifications in the proopiomelanocortin gene (POMC): a study with children in Tanzania. Dev. Psychopathol. doi: 10.1017/S0954579415001248. [Epub ahead of print].

Heim, C., and Binder, E. B. (2012). Current research trends in early life stress and depression: Review of human studies on sensitive periods, geneenvironment interactions, and epigenetics. Exp. Neurol. 233, 102-111. doi: 10.1016/j.expneurol.2011.10.032

Hernán, M. A., Hernández-Diaz, S., Werler, M. M., and Mitchell, A. A. (2002). Causal knowledge as a prerequisite for confounding evaluation: an application to birth defects epidemiology. Am. J. Epidemiol. 155, 176-184. doi: 10.1093/aje/155.2.176

Horan, J. M., and Widom, C. S. (2014). Cumulative childhood risk and adult functioning in abused and neglected children grown up. Dev. Psychopathol. 27, 927-941. doi: 10.1017/S095457941400090X

Horwitz, A. V., Widom, C. S., McLaughlin, J., and White, H. R. (2001). The impact of childhood abuse and neglect on adult mental health: a prospective study. J. Health Soc. Behav. 42, 184-201. doi: 10.2307/3090177

Hovens, J. G. F. M., Wiersma, J. E., Giltay, E. J., Van Oppen, P., Spinhoven, P., Penninx, B. W. J. H., et al. (2010). Childhood life events and childhood trauma in adult patients with depressive, anxiety and comorbid disorders vs. controls. Acta Psychiatrica Scand. 122, 66-74. doi: 10.1111/j.1600-0447.2009.01491.x
Hoyos, A., and Narayan, A. (2011). Inequality of opportunities among children: how much does gender matter? Retrieved from http://siteresources.worldbank. org/INTPOVERTY/Resources/Role_of_Gender_WDR_bground_June_27, 2011.pdf

Huettner, F., and Sunder, M. (2012). Axiomatic arguments for decomposing goodness of fit according to Shapley and Owen values. Electron. J. Stat. 6, 1239-1250. doi: 10.1214/12-EJS710

Huh, H., Kim, S.-Y., Yu, J., and Chae, J.-H. (2014). Childhood trauma and adult interpersonal relationship problems in patients with depression and anxiety disorders. Ann. Gen. Psychiatry 13:26. doi: 10.1186/s12991-014-0026-y

Hussey, J. M., Chang, J. J., and Kotch, J. B. (2006). Child maltreatment in the united states: prevalence, risk factors, and adolescent health consequences. Pediatrics 118, 933-942. doi: 10.1542/peds.2005-2452

Jacobsen, B. K., Eggen, A. E., Mathiesen, E. B., Wilsgaard, T., and Njølstad, I. (2012). Cohort profile: the tromsø study. Int. J. Epidemiol. 41, 961-967. doi: 10.1093/ije/dyr049

Jiang, Z., and VanderWeele, T. J. (2015). When is the difference method conservative for assessing mediation? Am. J. Epidemiol. 182, 105-108. doi: 10.1093/aje/kwv059

Judd, C. M., and Kenny, D. A. (1981). Process analysis: estimating mediation in treatment evaluations. Eval. Rev. 5, 602-619. doi: 10.1177/0193841X8100500502

Kaufman, J. S., Maclehose, R. F., and Kaufman, S. (2004). A further critique of the analytic strategy of adjusting for covariates to identify biologic mediation. Epidemiol. Perspect. Innov. 1:4. doi: 10.1186/1742-5573-1-4

Kessler, R. C., and Magee, W. J. (1994). Childhood family violence and adult recurrent depression. J. Health Soc. Behav. 35, 13-27. Available online at: http:// www.jstor.org/stable/2137332

Korbin, J. E., Coulton, C. J., Chard, S., Platt-Houston, C., and Su, M. (1998). Impoverishment and child maltreatment in African American and European American neighborhoods. Dev. Psychopathol. 10, 215-233. Available online at: http://journals.cambridge.org/action/displayAbstract?fromPage=online\&aid= 43545\&fileId $=$ S0954579498001588

Krastins, A., Francis, A. J. P., Field, A. M., and Carr, S. N. (2014). Childhood predictors of adulthood antisocial personality disorder symptomatology. Aust. Psychol. 49, 142-150. doi: 10.1111/ap.12048

Kvamme, J.-M., Grønli, O., Florholmen, J., and Jacobsen, B. K. (2011). Risk of malnutrition is associated with mental health symptoms in community living elderly men and women: the tromsø study. BMC Psychiatry 11:112. doi: 10.1186/1471-244X-11-112

Lamu, A. N., and Olsen, J. A. (2016). The relative importance of health, income and social relations for subjective well-being: an integrative analysis. Soc. Sci. Med. 152, 176-185. doi: 10.1016/j.socscimed.2016.01.046

Landes, S. D., Ardelt, M., Vaillant, G. E., and Waldinger, R. J. (2014). Childhood adversity, midlife generativity, and later life well-being. J. Gerontol. B Psychol. Sci. Soc. Sci. 69, 942-952. doi: 10.1093/geronb/gbu055

Luntz, B. K., and Widom, C. S. (1994). Antisocial personality disorder in abused and neglected children grown up. Am. J. Psychiatry 151, 670-674. doi: 10.1176/ajp.151.5.670

Luo, Y., and Waite, L. J. (2005). The impact of childhood and adult SES on physical, mental, and cognitive well-being in later life. J. Gerontol. 60B, 93-101. doi: 10.1093 /geronb/60.2.S93

Luthar, S. S., Cicchetti, D., and Becker, B. (2000). The construct of resilience: a critical evaluation and guidelines for future work. Child Dev. 71, 543-562. doi: 10.1111/1467-8624.00164

Lykken, D., and Tellegen, A. (1996). Happiness is a stochastic phenomenon. Psychol. Sci. 7, 186-189. doi: 10.1111/j.1467-9280.1996.tb00355.x

MacKinnon, D. P. (2008). Introduction to Statistical Mediation Analysis. New York, NY: Taylor and Francis.

Marshall, S. W. (2007). Power for tests of interaction: effect of raising the Type I error rate. Epidemiol. Perspect. Innov. 4, 1-7. doi: 10.1186/1742-5573-4-4

Martin, H., Teicher, M. D., Ph.D., Jacqueline, A., Samson, P. D., Ann Polcari, R. N., et al. and McGreenery, C. E. (2006). Sticks, stones, and hurtful words: relative effects of various forms of childhood maltreatment. Am. J. Psychiatry 163, 993-1000. doi: 10.1176/ajp.2006.163.6.993

Martinussen, T. (2009). Dynamic path analysis for event time data: large sample properties and inference. Lifetime Data Anal. 16, 85-101. doi: 10.1007/s10985$009-9128-2$ 
May-Ling, J., Loxton, D., and McLaughlin, D. (2015). Trauma exposure and the subsequent risk of coronary heart disease among mid-aged women. J. Behav. Med. 38, 57-65. doi: 10.1007/s10865-014-9577-2

McCauley, J., Kern, D. E., Kolodner, K., Dill, L., Schroeder, A. F., DeChant, H. K., et al. (1997). Clinical characteristics of women with a history of childhood abuse: Unhealed wounds. J. Am. Med. Assoc. 277, 1362-1368. doi: 10.1001/jama.1997.03540410040028

McLaughlin, K. A., Conron, K. J., Koenen, K. C., and Gilman, S. E. (2010). Childhood adversity, adult stressful life events, and risk of pastyear psychiatric disorder: a test of the stress sensitization hypothesis in a population-based sample of adults. Psychol. Med. 40, 1647-1658. doi: 10.1017/S0033291709992121

McLeod, J. D. (1991). Childhood parental loss and adult depression. J. Health Soc. Behav. 32, 205-220. doi: 10.2307/2136804

Miettinen, O., and Cook, E. F. (1981). Confounding: essense and detection. Am. J. Epidemiol. 114, 593-603. Available online at: http://aje.oxfordjournals.org/ content/114/4/593

Miller, B. A., Downs, W. R., and Testa, M. (1993). Interrelationships between victimization experiences and women's alcohol use. J. Stud. Alcohol Suppl. 11, 109-117. doi: 10.15288/jsas.1993.s11.109

Mock, S. E., and Arai, S. M. (2011). Childhood trauma and chronic illness in adulthood: mental health and socioeconomic status as explanatory factors and buffers. Front. Psychol. 1:246. doi: 10.3389/fpsyg.2010.00246

Monnat, S. M., and Chandler, R. F. (2015). Long-term physical health consequences of adverse childhood experiences. Sociol. Q. 56, 723-752. doi: $10.1111 /$ tsq. 12107

Morgan, C., Reininghaus, U., Fearon, P., Hutchinson, G., Morgan, K., Dazzan, P., et al. (2014). Modelling the interplay between childhood and adult adversity in pathways to psychosis: initial evidence from the AESOP study. Psychol. Med. 44, 407-419. doi: 10.1017/S0033291713000767

Morton, P. M., Mustillo, S. A., and Ferraro, K. F. (2014). Does childhood misfortune raise the risk of acute myocardial infarction in adulthood? Soc. Sci. Med. 104, 133-141. doi: 10.1016/j.socscimed.2013.11.026

Mullen, P. E., Martin, J. L., Anderson, J. C., Romans, S. E., and Herbison, G. P. (1996). The long-term impact of the physical, emotional, and sexual abuse of children: a community study. Child Abuse Neglect 20, 7-21. doi: 10.1016/01452134(95)00112-3

Mäkinen, T., Laaksonen, M., Lahelma, E., and Rahkonen, O. (2006). Associations of childhood circumstances with physical and mental functioning in adulthood. Soc. Sci. Med. 62, 1831-1839. doi: 10.1016/j.socscimed.2005.08.040

Ney, P. G. (1987). Does verbal abuse leave deeper scars: a study of children and parents. Can. J. Psychiatry 32, 371-378.

Nguyen, Q. C., Osypuk, T. L., Schmidt, N. M., Glymour, M. M., and Tchetgen Tchetgen, E. J. (2015). Practical guidance for conducting mediation analysis with multiple mediators using inverse odds ratio weighting. Am. J. Epidemiol. 181, 349-356. doi: 10.1093/aje/kwu278

Norman, R. E., Byambaa, M., De, R., Butchart, A., Scott, J., and Vos, T. (2012). The long-term health consequences of child physical abuse, emotional abuse, and neglect: a systematic review and meta-analysis. PLoS Med. 9:e1001349. doi: 10.1371/journal.pmed.1001349

Nurius, P. S., Green, S., Logan-Greene, P., and Borja, S. (2015). Life course pathways of adverse childhood experiences toward adult psychological wellbeing: a stress process analysis. Child Abuse Neglect 45, 143-153. doi: 10.1016/j.chiabu.2015.03.008

Pang, M., Kaufman, J. S., and Platt, R. W. (2013). Studying noncollapsibility of the odds ratio with marginal structural and logistic regression models. Stat. Methods Med. Res. doi: 10.1177/0962280213505804. [Epub ahead of print].

Park, A., Fuhrer, R., and Quesnel-Vallée, A. (2013). Parents' education and the risk of major depression in early adulthood. Soc. Psychiatry Psychiatr. Epidemiol. 48, 1829-1839. doi: 10.1007/s00127-013-0697-8

Pavela, G., and Latham, K. (2015). Childhood conditions and multimorbidity among older adults. J. Gerontol. B Psychol. Sci. Soc. Sci. doi: 10.1093/geronb/gbv028. [Epub ahead of print].

Pearl, J. (2012). The causal mediation formula-a guide to the assessment of pathways and mechanisms. Prev. Sci. 13, 426-436. doi: 10.1007/s11121-0110270-1

Raposo, S. M., Mackenzie, C. S., Henriksen, C. A., and Afifi, T. O. (2014). Time does not heal all wounds: older adults who experienced childhood adversities have higher odds of mood, anxiety, and personality disorders. Am. J. Geriatric Psychiatry 22, 1241-1250. doi: 10.1016/j.jagp.2013.04.009

Robins, J. M., and Greenland, S. (1992). Identifiability and exchangeability for direct and indirect effects. Epidemiology 3, 143-155. doi: 10.1097/00001648199203000-00013

Robins, L. N. (1978). Sturdy childhood predictors of adult antisocial behaviour: replications from longitudinal studies. Psychol. Med. 8, 611-622. doi: $10.1017 /$ S0033291700018821

Rothman, K. J. (1990). No adjustments are needed for multiple comparisons. Epidemiology 1, 43-46. doi: 10.1097/00001648-19900100000010

Salinas-Miranda, A. A., Salemi, J. L., King, L. M., Baldwin, J. A., Berry, E. L., Austin, D. A., et al. (2015). Adverse childhood experiences and health-related quality of life in adulthood: revelations from a community needs assessment. Health Qual. Life Outcomes 13, 1-12. doi: 10.1186/s12955-015-0323-4

Saunders, B. E., and Adams, Z. W. (2014). Epidemiology of traumatic experiences in childhood. Child Adolescent Psychiatric Clin. 23, 167-184. doi: 10.1016/j.chc.2013.12.003

Schilling, E. A., Aseltine, R. H., and Gore, S. (2007). Adverse childhood experiences and mental health in young adults: a longitudinal survey. BMC Public Health 7:30. doi: 10.1186/1471-2458-7-30

Schilling, E. A., Aseltine, R. H., and Gore, S. (2008). The impact of cumulative childhood adversity on young adult mental health: measures, models, and interpretations. Soc. Sci. Med. 66, 1140-1151. doi: 10.1016/j.socscimed.2007.11.023

Schilling, S., and Christian, C. W. (2014). Child physical abuse and neglect. Child Adolescent Psychiatric Clin. 23, 309-319. doi: 10.1016/j.chc.2014.01.001

Seligman, M. E. P. (2012). Flourish: A Visionary New Understanding of Happiness and Well-being. New York, NY: Free Press.

Shapley, L. S. (1953). “A Value for N-person Games," in Contributions to the Theory of Games (AM-28), Volume II, eds H. W. Kuhn and A. W. Tucker (Princeton, NJ: Princeton University Press), 307-317.

Shaw, B. A., and Krause, N. (2002). Exposure to physical violence during childhood, aging, and health. J. Aging Health 14, 467-494. doi: $10.1177 / 089826402237179$

Sheikh, M. A. (2015). Childhood trauma and adult health and wellbeing. Eur. J. Public Health 25(Suppl. 3). Available online at: http://eurpub.oxfordjournals. org/content/25/suppl_3/ckv176.301

Sheikh, M. A., Abelsen, B., and Olsen, J. A. (2014). Role of respondents' education as a mediator and moderator in the association between childhood socioeconomic status and later health and wellbeing. BMC Public Health 14, 1172. doi: 10.1186/1471-2458-14-1172

Sheikh, M. A., Lund, E., and Braaten, T. (2016). Test-retest reliability of selfreported diabetes diagnosis in the Norwegian Women and Cancer Study: a population-based longitudinal study $(\mathrm{n}=33,919)$. SAGE Open Med. 4, 1-11. doi: $10.1177 / 2050312115622857$

Shin, S. H., Lee, S., Jeon, S.-M., and Wills, T. A. (2015). Childhood emotional abuse, negative emotion-driven impulsivity, and alcohol use in young adulthood. Child Abuse Neglect 50, 94-103. doi: 10.1016/j.chiabu.2015. 02.010

Shonkoff, J. P., and Garner, A. S. (2011). The lifelong effects of early childhood adversity and toxic stress. Pediatrics 129, e232-e246. doi: 10.1542/peds.20112663

Shorrocks, A. F. (1982). Inequality decomposition by factor components. Econometrica 50, 193-211. doi: 10.2307/1912537

Shorrocks, A. F. (2012). Decomposition procedures for distributional analysis: a unified framework based on the Shapley value. J. Econ. Inequality 11, 99-126. doi: 10.1007/s10888-011-9214-Z

Silverman, A. B., Reinherz, H. Z., and Giaconia, R. M. (1996). The long-term sequelae of child and adolescent abuse: a longitudinal community study. Child Abuse Neglect 20, 709-723. doi: 10.1016/0145-2134(96)00059-2

Slopen, N., Williams, D. R., Seedat, S., Moomal, H., Herman, A., and Stein, D. J. (2010). Adversities in childhood and adult psychopathology in the South Africa Stress and Health Study: Associations with first-onset DSMIV disorders. Soc. Sci. Med. 71, 1847-1854. doi: 10.1016/j.socscimed.2010. 08.015

Spinazzola, J., Hodgdon, H., Liang, L.-J., Ford, J. D., Layne, C. M., Pynoos, R., et al. (2014). Unseen wounds: the contribution of psychological maltreatment to 
child and adolescent mental health and risk outcomes. Psychol. Trauma Theory Res. Practice Policy 6, S18-S28. doi: 10.1037/a0037766

Springer, K. W. (2009). Childhood physical abuse and midlife physical health: Testing a multi-pathway life course model. Soc. Sci. Med. 69, 138-146. doi: 10.1016/j.socscimed.2009.04.011

StataCorp, (2013). Stata Multiple-Imputation Reference Manual: Release 13. Retrieved from http://www.stata.com/manuals13/mi.pdf

Strand, B. H., Dalgard, O. S., Tambs, K., and Rognerud, M. (2003). Measuring the mental health status of the Norwegian population: a comparison of the instruments SCL-25, SCL-10, SCL-5 and MHI-5 (SF-36). Nord. J. Psychiatry 57, 113-118. doi: 10.1080/08039480310000932

Susser, M. (1973). Causal Thinking in the Health Sciences: Concepts and Strategies of Epidemiology. New York, NY: Oxford University Press.

Szklo, M., and Nieto, J. (2000). Epidemiology: Beyond the Basics. Gaithersburg, MD: Aspen Publishers.

The EuroQol Group. (1990). EuroQol-a new facility for the measurement of health-related quality of life. Health Policy 16, 199-208. doi: 10.1016/01688510(90)90421-9

Thoresen, S., Myhre, M., Wentzel-Larsen, T., Aakvaag, H. F., and Hjemdal, O. K. (2015). Violence against children, later victimisation, and mental health: a cross-sectional study of the general Norwegian population. Eur. J. Psychotraumatol. 6:26259. doi: 10.3402/ejpt.v6.26259

van Dam, D. S., van Nierop, M., Viechtbauer, W., Velthorst, E., van Winkel, R., Bruggeman, R., et al. (2015). Childhood abuse and neglect in relation to the presence and persistence of psychotic and depressive symptomatology. Psychol. Med. 45, 1363-1377. doi: 10.1017/S0033291714001561

van Nierop, M., van Os, J., Gunther, N., van Zelst, C., de Graaf, R., ten Have, M., et al. (2014). Does social defeat mediate the association between childhood trauma and psychosis? Evidence from the NEMESIS-2 Study. Acta Psychiatrica Scand. 129, 467-476. doi: 10.1111/acps.12212

Veronese, G., and Castiglioni, M. (2015). 'When the doors of Hell close': Dimensions of well-being and positive adjustment in a group of Palestinian children living amidst military and political violence. Childhood 22, 6-22. doi: $10.1177 / 0907568213512692$

Veronese, G., Castiglioni, M., Barola, G., and Said, M. (2012a). Living in the shadow of occupation: Life satisfaction and positive emotion as protective factors in a group of Palestinian school children. Child. Youth Serv. Rev. 34, 225-233. doi: 10.1016/j.childyouth.2011.10.002

Veronese, G., Castiglioni, M., Tombolani, M., and Said, M. (2012b). 'My happiness is the refugee camp, my future Palestine': optimism, life satisfaction and perceived happiness in a group of Palestinian children. Scand. J. Caring Sci. 26, 467-473. doi: 10.1111/j.1471-6712.2011.00951.x

Veronese, G., Natour, M., and Said, M. (2012c). Positive emotions and life satisfaction in Palestinian children growing up amid political and military violence: a pilot study. Lancet 380(Suppl. 1), S16. doi: 10.1016/S01406736(13)60198-1

Walker, E. A., Gelfand, A., Katon, W. J., Koss, M. P., Von Korff, M., Bernstein, D., et al. (1999). Adult health status of women with histories of childhood abuse and neglect. Am. J. Med. 107, 332-339. doi: 10.1016/S0002-9343(99)00235-1

Welch, B. L. (1947). The generalisation of student's problems when several different population variances are involved. Biometrika 34, 28-35. doi: 10.1093/biomet/34.1-2.28

Widom, C. S., and Hiller-Sturmhofel, S. (2001). Alcohol abuse as a risk factor for and consequence of child abuse. Alcohol Res. Health 25, 52-57. Available online at: http://pubs.niaaa.nih.gov/publications/arh25-1/52-57.htm

Widom, C. S., Ireland, T., and Glynn, P. J. (1995). Alcohol abuse in abused and neglected children followed-up: are they at increased risk? J. Stud. Alcohol 56, 207-217. doi: 10.15288/jsa.1995.56.207

Widom, C. S., and White, H. R. (1997). Problem behaviours in abused and neglected children grown up: prevalence and co-occurrence of substance abuse, crime and violence. Crim. Behav. Mental Health 7, 287-310. doi: 10.1002/cbm.191

Widom, C. S., White, H. R., Czaja, S. J., and Marmorstein, N. R. (2007). Long-term effects of child abuse and neglect on alcohol use and excessive drinking in middle adulthood. J. Stud. Alcohol Drugs 68, 317-326. doi: 10.15288/jsad.2007.68.317

Wilcox, R. R., Charlin, V. L., and Thompson, K. L. (1986). New monte carlo results on the robustness of the anova $\mathrm{f}, \mathrm{w}$ and $\mathrm{f}$ statistics. Commun. Stat. Simulation Comput. 15, 933-943. doi: 10.1080/03610918608812553

Williams, L. M. (1994). Recall of childhood trauma: a prospective study of women's memories of child sexual abuse. J. Consult. Clin. Psychol. 62, 1167-1176. doi: 10.1037/0022-006X.62.6.1167

Wright, S. (1934). The method of path coefficients. Ann. Math. Stat. 5, 161-215.

Zajacova, A., and Dowd, J. B. (2011). Reliability of Self-rated Health in US Adults. Am. J. Epidemiol. 174, 977-983. doi: 10.1214/aoms/1177732676

Zou, G. (2004). A modified poisson regression approach to prospective studies with binary data. Am. J. Epidemiol. 159, 702-706. doi: 10.1093/aje/kwh090

Conflict of Interest Statement: The authors declare that the research was conducted in the absence of any commercial or financial relationships that could be construed as a potential conflict of interest.

Copyright (c) 2016 Sheikh, Abelsen and Olsen. This is an open-access article distributed under the terms of the Creative Commons Attribution License (CC BY). The use, distribution or reproduction in other forums is permitted, provided the original author(s) or licensor are credited and that the original publication in this journal is cited, in accordance with accepted academic practice. No use, distribution or reproduction is permitted which does not comply with these terms. 